\title{
Inside Speech: Multisensory and Modality-specific Processing of Tongue and Lip Speech Actions
}

\author{
Avril Treille ${ }^{1}$, Coriandre Vilain ${ }^{1}$, Thomas Hueber ${ }^{1}$, \\ Laurent Lamalle $^{2,3}$, and Marc Sato ${ }^{4}$
}

\begin{abstract}
Action recognition has been found to rely not only on sensory brain areas but also partly on the observer's motor system. However, whether distinct auditory and visual experiences of an action modulate sensorimotor activity remains largely unknown. In the present sparse sampling fMRI study, we determined to which extent sensory and motor representations interact during the perception of tongue and lip speech actions. Tongue and lip speech actions were selected because tongue movements of our interlocutor are accessible via their impact on speech acoustics but not visible because of its position inside the vocal tract, whereas lip movements are both "audible" and visible. Participants were presented with auditory, visual, and audiovisual speech actions, with the visual inputs related to either a sagittal view of the tongue movements or a facial view of the lip movements of a speaker, previously recorded by an ultrasound imaging system and a video camera. Although the
\end{abstract}

\section{INTRODUCTION}

Through life experiences, we learn about which sensory features of actions are most behaviorally relevant for successful categorization and recognition. However, one intriguing question is to know what happens when an action is not accessible to one sensor in the daily experience-typically, accessible via their impact on acoustics but not visible. From this question, this fMRI study aimed at determining multisensory and modalityspecific processing of tongue and lip speech actions, with tongue movements of our interlocutor usually "audible" but not visible and lip movements both "audible" and visible.

\section{Motor Resonance in Biological Action Recognition}

Although information from different sensory modalities, such as sight and/or sound, is processed in unisensory and multisensory brain areas, several studies have iden-

${ }^{1}$ CNRS UMR 5216 \& Grenoble Université, ${ }^{2}$ Université GrenobleAlpes \& CHU de Grenoble, ${ }^{3}$ CNRS UMS 3552, Grenoble, France, ${ }^{4}$ CNRS UMR 7309 \& Aix-Marseille Université

neural networks involved in visual visuo-lingual and visuo-facial perception largely overlapped, stronger motor and somatosensory activations were observed during visuo-lingual perception. In contrast, stronger activity was found in auditory and visual cortices during visuo-facial perception. Complementing these findings, activity in the left premotor cortex and in visual brain areas was found to correlate with visual recognition scores observed for visuo-lingual and visuo-facial speech stimuli, respectively, whereas visual activity correlated with RTs for both stimuli. These results suggest that unimodal and multimodal processing of lip and tongue speech actions rely on common sensorimotor brain areas. They also suggest that visual processing of audible but not visible movements induces motor and visual mental simulation of the perceived actions to facilitate recognition and/or to learn the association between auditory and visual signals.

tified a central role for motor representations in action recognition. These results appear in keeping with the long-standing proposal that perception and action are two closely linked processes and with more recent neurophysiological perspectives based on the existence of mirror neurons in nonhuman primates and on an actionperception matching system in humans (for reviews, see Rizzolatti \& Craighero, 2004; Rizzolatti, Fogassi, \& Gallese, 2001). Mirror neurons are polymodal visuomotor or audio-visuomotor neurons in the ventral premotor and posterior parietal cortices (areas F5 and PF) of the macaque monkey, which have been shown to discharge both when the monkey performs hand or mouth actions and when it views or listens to similar actions made by another individual (e.g., Fogassi et al., 2005; Ferrari, Gallese, Rizzolatti, \& Fogassi, 2003; Keysers et al., 2003; Kohler et al., 2002; Gallese, Fadiga, Fogassi, \& Rizzolatti, 1996; Rizzolatti, Fadiga, Gallese, \& Fogassi, 1996; Di Pellegrino, Fadiga, Fogassi, Gallese, \& Rizzolatti, 1992). The existence of mirror neurons thus suggests that action observation partly involves the same neural circuits that are used in action performance. Since then, auditoryvocal mirror neurons have also been recorded in nonmammalian vertebrates (Prather, Peters, Nowicki, \& 
Mooney, 2008), and numerous neurophysiological and brain imaging experiments have provided evidence for the existence of a frontoparietal action-perception matching system in humans (Rizzolatti \& Craighero, 2004). Altogether, these studies demonstrate that sensory information related to biological movements is not only processed in sensory regions but also in the observer's motor system and partly relies on his or her own motor knowledge.

From that view, a stronger activity in the premotor cortex and the posterior parietal cortex is observed during visual and audiovisual perception of biological movements, compared with nonbiological movements (e.g., Saygin, 2007; Calvert, Campbell, \& Brammer, 2000; Howard et al., 1996). Moreover, hearing action-related sounds like knock on the door or hand clapping or more complex auditory material like a piano piece also activates motor and premotor regions (e.g., Lahav, Saltzman, \& Schlaug, 2007; Pizzamiglio et al., 2005; Aziz-Zadeh, Iacoboni, Zaidel, Wilson, \& Mazziotta, 2004; Haueisen \& Knösche, 2001). These results support the long-standing theoretical proposal that specific constraints and regularity in biological motion and kinematics are used in action recognition (Viviani \& Stucchi, 1992; Johansson, 1973), even when they are roughly represented by point lights (Loula, Prasad, Harber, \& Shiffrar, 2005; Beardsworth \& Buckner, 1981). Furthermore, action recognition seems to rely not only on biological features per se but also more specifically on a motor repertoire shared by individuals of the same species and related to their relevant physical and/or communicative ability for perceptual processing. For example, Tai, Scherfler, Brooks, Sawamoto, and Castiello (2004) observed premotor activity during the sight of human hand grasp but not during the sight of the same action performed by a robot, which supports the use of a human biological motor repertoire in action recognition. On their side, Buccino et al. (2004) showed that the observation of a biting action performed by humans, monkeys, or dogs induced motor activity in humans, contrary to what happens during the observation of dog-specific barking movements. Calvo-Merino and colleagues (Calvo-Merino, Grèzes, Glaser, Passingham, \& Haggard, 2006; CalvoMerino, Glaser, Grèzes, Passingham, \& Haggard, 2005) also showed that, apart from visual familiarity, the involvement of motor areas during action observation strongly relies on motor learning. They indeed observed, among other parietal and cerebellar regions, stronger premotor cortex activity when male dancers viewed dance movements from their own motor repertoire compared with female dance movements that they often saw but never performed. Although a causal role of the motor system during action recognition is still debated, these fMRI studies suggest a strong correlation between motor activity and action observation.

\section{Motor Resonance Extends to Speech Action}

Speech is a special type of biological human actions that interfaces with the linguistic system and requires an accu- rate control of our speech articulators (i.e., the lips, the tongue, the jaw, the velum, and the larynx). As with other type of actions, such as grasping or walking, several neuroimaging studies suggest that speech recognition is also partly mediated by the motor system. Brain areas involved in the planning and execution of speech actions (i.e., the posterior part of the left inferior frontal gyrus, the premotor and primary motor cortices) have indeed shown neural responses during auditory speech perception (e.g., Pulvermuller et al., 2006; Wilson \& Iacoboni, 2006; Wilson, Saygin, Sereno, \& Iacoboni, 2004). In addition, repetitive and double-pulse TMS studies also suggest that speech motor regions are causally recruited during auditory speech categorization, especially in case of complex situations (e.g., the perception of acoustically ambiguous syllables or when phonological segmentation or working memory processes are strongly required abski et al., 2013; d'Ausilio, Bufalari, Salmas, \& Fadiga 1; d'Ausilio et al., 2009; Möttönen \& Watkins, 2009; Sato, Tremblay, \& Gracco, 2009; Meister, Wilson, Deblieck, Wu, \& Iacoboni, 2007). Taken together, these results support the idea that our motor knowledge used to produce speech sounds helps to partly constraint phonetic decoding of the sensory inputs, as proposed in motor and sensorimotor theories of speech perception and language comprehension (Pickering \& Garrod, 2013; Schwartz, Ménard, Basirat, \& Sato, 2012; Skipper, Van Wassenhove, Nussman, \& Small, 2007; Liberman \& Mattingly, 1985).

Importantly, speech provides visual as well as auditory information. Although humans are proficient to extract phonetic features from the acoustic signal alone and, to a lesser extent, are capable to partly read on lips when audition is lacking, interactions between auditory and visual modalities are beneficial in speech perception. Neuroimaging studies demonstrate the existence of specific brain areas playing a key role in the audiovisual integration of speech. Notably, activity within unisensory visual and auditory regions (the visual motion-sensitive cortex, V5/MT, and the Heschl's gyrus) as well as within multisensory regions (the posterior parts of the left superior temporal gyrus/STS [pSTS/pSTG]) is modulated during audiovisual speech perception, when compared with auditory and visual unimodal conditions (Skipper et al., 2007; Skipper, Nusbaum, \& Small, 2005; Callan et al., 2003, 2004; Calvert et al., 2000). Because pSTS/pSTG displays supra-additive and subadditive responses during congruent and incongruent stimuli presentation, it has been proposed that both visual and auditory speech information are integrated in these high-level multisensory integrative regions and that modulations of neuronal responses within the sensory-specific cortices would then be due to feedback projections from this multisensory region. Such modulations would represent the physiological correlates of the perceptual changes experienced after multisensory integration (e.g., Beauchamp, 2005; Beauchamp, Argall, Bodurka, Duyn, \& Martin, 2004; Beauchamp, Lee, Argall, \& Martin, 2004; Calvert 
et al., 2000). In addition, premotor and motor cortices, known to play a crucial role in speech production, might also play a key role in audiovisual integration mechanisms in speech perception (e.g., Sato, Buccino, Gentilucci, \& Cattaneo, 2010; Watkins \& Paus, 2004; Calvert \& Campbell, 2003; Watkins, Strafella, \& Paus, 2003; Campbell et al., 2001). From that view, Skipper and colleagues (2005, 2007) observed stronger activation in speech motor regions during audiovisual speech perception, compared with auditory and visual unimodal conditions. Callan and colleagues $(2003,2004)$ also demonstrated increased motor activity under adverse listening or viewing conditions during bimodal speech presentation. In addition, increased activity or, on the contrary, subadditive responses in the Broca's area have also been reported during the perception of incongruent compared with congruent audiovisual speech stimuli (Pekkola et al., 2006; Ojanen et al., 2005) or compared with unimodal speech stimuli (Calvert et al., 2000). From these results, multisensory areas and speech motor regions appear as good candidates for brain areas where acoustic and visual speech signals can interact, which suggests a possible integration between incoming sensory signals and speech motor knowledge specific to the listener.

\section{Motor Resonance for Audible but Hidden Actions}

If the motor system is indeed involved in multisensory integration, what happens when an action is not accessible to one sensor in the daily experience-typically audible but not visible? We know from the classic studies by Meltzoff and Moore $(1977,1983)$ that 3-week-old infants, and even newborns, are able to associate from birth a visual action they have never seen, like lip and tongue protrusion, with motor commands, possibly through the use of their proprioceptive system. This indirectly suggests that, in adults, the sensorimotor network could play a role in the visual processing of audible but not visible actions by enabling a transfer of motor knowledge toward an inferred visual experience, possibly combined with past auditory and somatosensory experiences.

Lips and tongue are two perfect articulators to test this specific question. First, we have an excellent somatosensory-motor control of both articulators, notably during speaking. Second, because of their position inside the vocal tract, tongue movements of our interlocutor are usually "audible" but not visible, whereas lip movements are both "audible" and visible. Interestingly, few behavioral studies using virtual tongue movements or ultrasound images of tongue movements demonstrate stronger speech learning with a visual tongue feedback (Katz \& Mehta, 2015) and an enhancement of auditory stimuli discrimination when they are matched with related visual tongue movements compared with auditory-only or incongruent audio-visuo-lingual stimuli (d'Ausilio, Bartoli, Maffongelli, Berry, \& Fadiga, 2014; Badin, Tarabalka, Elisei, \& Bailly, 2010).
To determine the neural networks involved in the perceptual processing of visuo-lingual and visuo-facial actions, an fMRI study on unimodal and multimodal speech perception was conducted. Participants had to recognize auditory, visual, or audiovisual speech stimuli, with the visual presentation related to either a sagittal view of the tongue movements or a facial view of the lip movements of a speaker, with lingual and facial movements previously recorded by an ultrasound imaging system and a video camera. Our first goal was to determine the shared neural correlates of visual and audiovisual tongue and lip movements as well as the neural specificity of lingual perception compared with facial perception. We also examined possible similarities and differences in the integration between audiovisuo-lingual and audio-visuo-facial modalities and the correlation between neural activity and visual syllable recognition scores.

\section{METHODS \\ Participants}

Fourteen healthy adults (seven women and seven men with a mean age of 26 years, ranging from 18 to 44 years), who are native French speakers, participated in the study after giving their informed consent. Two participants were removed from the study because of excessive head movements or technical problems during MRI acquisition. All participants were right-handed according to standard handedness inventory (Oldfield, 1971), had normal or corrected-to-normal vision, and reported no history of speaking, hearing, or motor disorders. The protocol was approved by the Grenoble University Ethical Committee with all participants screened for neurological, psychiatric, and other possible medical problems and contraindications to MRI. None of the participants were experienced with visuo-lingual ultrasound images.

\section{Stimuli}

Before the experiment, multiple utterances of $/ \mathrm{pa} /, / \mathrm{ta} /$, and $/ \mathrm{ka} /$ syllables were individually recorded by one male and one female speakers in a soundproof room. These syllables were selected based on previous studies on audiovisual speech perception to ensure a gradient of visuo-labial saliency (with notably the bilabial/p/ consonant known to be more visually salient than alveolar $/ \mathrm{t} /$ and velar $/ \mathrm{k}$ / consonants). Regarding visuo-lingual saliency, $/ \mathrm{t} /$ and $/ \mathrm{k} /$ consonants have more visible tongue movement than $/ \mathrm{p} /$ because of the involvement of the apex or the dorsum of the tongue during alveolar or velar occlusion (see Figure 1).

Synchronous recordings of auditory, visual, and ultrasound signals were acquired by the Ultraspeech system 


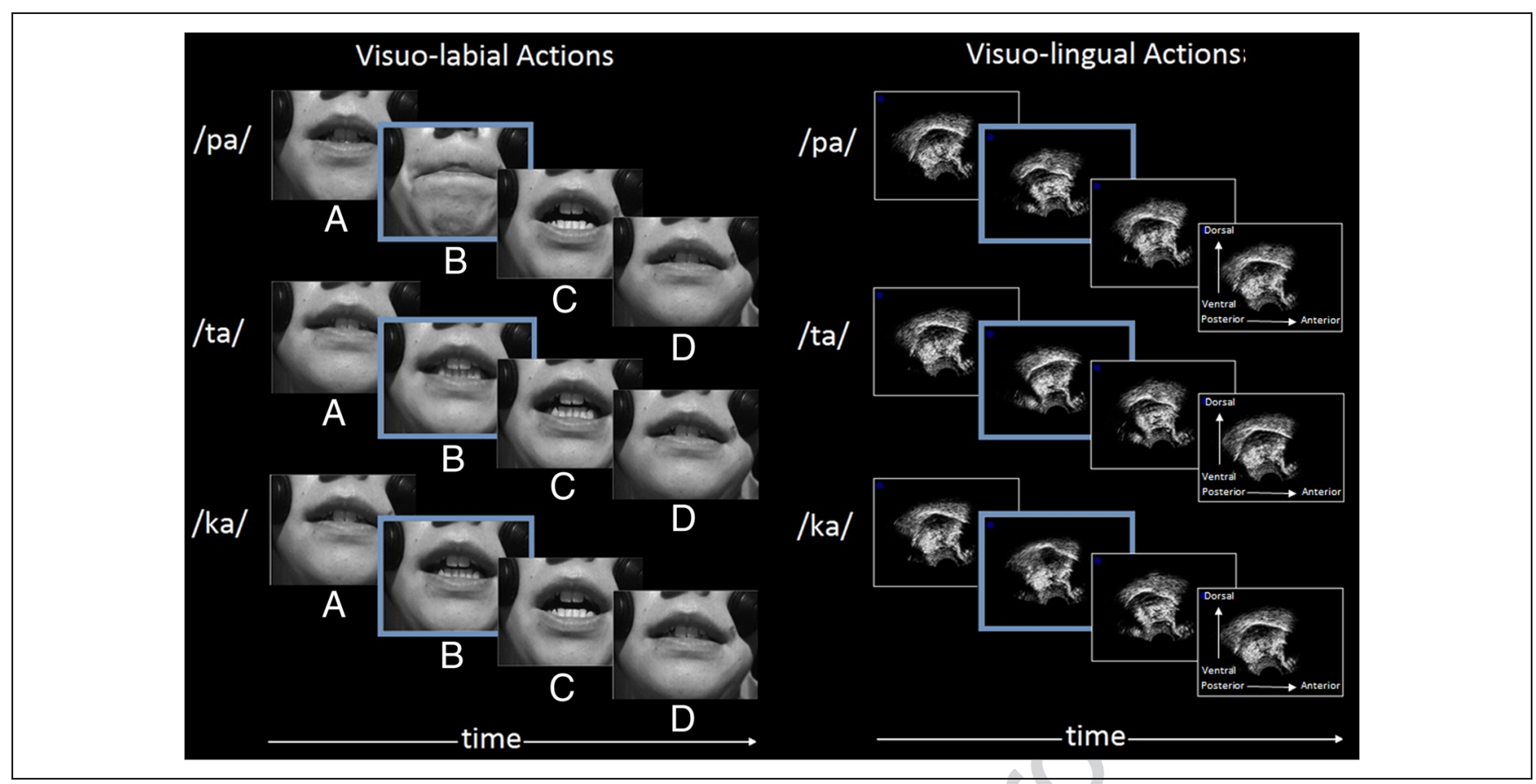

Figure 1. Examples of visual stimuli related to lip and tongue movements for /pa/, /ta/, and/ka/ syllables at four crucial moments: (A) initial neutral position, (B) closure of the vocal tract (in red, /pa/: bilabial occlusion; /ta/: alveolar occlusion, with tongue behind the teeth; /ka/: velar occlusion, with tongue against the palate), (C) vowel production with a maximum opening of the mouth and with the tongue at the back of the vocal tract, and (D) ending neutral position.

(Hueber, Chollet, Denby, \& Stone, 2008) composed of a Terason T3000 ultrasound scanner, a $140^{\circ}$ microconvex transducer with 128 elements (tongue movements acquired with a sampling rate of $60 \mathrm{fps}$ with a $320 \times 240$ pixel resolution), an industrial USB color camera (facial movements acquired with a sampling rate of $60 \mathrm{fps}$ with a $640 \times 480$ pixel resolution), and an external microphone connected to an RME Fireface 800 soundcard (audio digitizing at $44.1 \mathrm{kHz}$ with 16-bit quantization recording).

Two clearly articulated /pa/, /ta/, and / ka/ tokens were selected per speaker (with the speaker initiating each utterance from a neutral mid-open mouth position), providing 12 syllables altogether. Sixty stimuli were created consisting of the 12 distinct $/ \mathrm{pa} /, / \mathrm{ta} /$, and $/ \mathrm{ka} /$ syllables related to five conditions: an auditory condition (A), two visual conditions related to either facial (i.e., lip movements) or tongue movements of a speaker $\left(\mathrm{V}_{\mathrm{F}}, \mathrm{V}_{\mathrm{T}}\right)$, and two audiovisual conditions including either facial or tongue movements of a speaker $\left(\mathrm{AV}_{\mathrm{F}}, \mathrm{AV}_{\mathrm{T}}\right)$. The auditory signal intensities were normalized using a common maximal amplitude criterion, and each movie was 80 frames long (1333 msec). To limit possible effects of predictability, variability was introduced with different acoustic consonantal onsets (mean $=450 \mathrm{msec}, S D=193 \mathrm{msec}$ ), acoustic durations (mean $=514 \mathrm{msec}, S D=139 \mathrm{msec}$ ), visuo-facial onsets (mean $=250 \mathrm{msec}, S D=149 \mathrm{msec}$ ), and visuolingual onsets (mean $=276 \mathrm{msec}, S D=252 \mathrm{msec}$ ), while keeping temporal congruency between auditory and visual signals in audiovisual conditions.

\section{Procedure}

\section{Behavioral Experiment}

Before the fMRI session, participants were first presented with a subset of the recorded speech stimuli, with short explanations about the tongue movements during the production of $/ \mathrm{pa} /, / \mathrm{ta} /$, and $/ \mathrm{ka} /$ syllables and how these movements are imaged by the ultrasound system. They then underwent a three-alternative forced-choice identification task, having been instructed to categorize as quickly as possible each perceived syllable with their right hand. Participants sat in front of a computer monitor at a distance of approximately $50 \mathrm{~cm}$. The acoustic stimuli were presented at a comfortable sound level through headphones, with the same sound level set for all participants. The Presentation software (Neurobehavioral Systems, Albany, CA) was used to control the stimulus presentation and to record key responses. The experiment consisted of 60 trials presented in a randomized sequence, with 12 trials related to each modality of presentation $\left(A, V_{F}, V_{T}, A V_{F}\right.$, and $\left.A V_{T}\right)$. The intertrial interval was of $3 \mathrm{sec}$, and the response key designation was fully counterbalanced across participants. Importantly, participants did not receive any feedback regarding their performance.

\section{fMRI Experiment}

Immediately after the behavioral experiment, the fMRI session consisted of one anatomical scan and one functional 
run. During the functional run, participants were instructed to attentively listen to and/or watch speech stimuli related to $/ \mathrm{pa} /, / \mathrm{ta} /$, and $/ \mathrm{ka} /$ syllables presented in five different modalities $\left(A, V_{F}, V_{T}, A V_{F}\right.$, and $\left.A V_{T}\right)$. All stimuli were presented in silent interscanning periods because of sparse sampling acquisition, with the time interval between each stimulus onset and the midpoint of the following functional scan acquisition being set at $5 \mathrm{sec}$ (see below). There were 144 trials, with an 8-sec intertrial interval, consisting of 24 trials for each modality of presentation (with each syllable presented two times) and 24 trials related to a resting condition without any sensory stimulation.

\section{Data Acquisition}

Magnetic resonance images were acquired with a 3-T whole-body MR scanner (Philips Achieva T) Participants lay in the scanner with head movements 2 mimized with a standard birdcage 32-channel head coil and foam cushions. Visual stimuli were presented using the Presentation software (Neurobehavioral Systems, Albany, CA) and displayed on a screen situated behind the scanner via a mirror placed above the participant's eyes. Auditory stimuli were presented through the MR-confon audio system (www.mr-confon.de).

A high-resolution T1-weighted whole-brain structural image was acquired for each participant before the functional run (magnetization prepared rapid gradient echo, sagittal volume of $256 \times 224 \times 176 \mathrm{~mm}^{3}$ with a $1-\mathrm{mm}$ isotropic resolution, inversion time $=900 \mathrm{msec}$, two segments, segment repetition time $=2500 \mathrm{msec}$, segment duration $=1795 \mathrm{msec}$, repetition time $[\mathrm{TR}] /$ echo time $=$ $16 / 5$ msec with 35\% partial echo, flip angle $=30^{\circ}$ ).

Functional images were obtained in a subsequent functional run using a T2*-weighted EPI sequence with whole-brain coverage $(\mathrm{TR}=8 \mathrm{sec}$, acquisition time $=$ $3000 \mathrm{msec}$, echo time $=30 \mathrm{msec}$, flip angle $=90^{\circ}$ ). Each functional scan was composed of 53 axial slices parallel to the AC-PC plane acquired in noninterleaved order $(72 \times 72$ matrix, field of view $=216 \mathrm{~mm}, 3 \times$ $3 \mathrm{~mm}^{2}$ in-plane resolution with a slice thickness of $3 \mathrm{~mm}$ without gap). To reduce acoustic noise, a sparse sampling acquisition was used (Birn, Bandettini, Cox, \& Shaker, 1999; Hall et al., 1999). This acquisition technique is based on neurophysiological properties of the slowly rising hemodynamic response, which is estimated to occur with a 4- to 6-sec delay in case of speech perception bski et al., 2013; Zaehle et al., 2007). In this study, ional scanning therefore occurred only during a fraction of the TR, alternating with silent interscanning periods, where stimuli were presented. All conditions were presented in a pseudorandom sequence. In addition, three "dummy" scans at the beginning of the functional run were added to allow for equilibration of the MRI signal and were removed from the analyses.

\section{Data Analyses}

\section{Behavioral Analysis}

For each participant and modality, the percentage of correct responses and median RTs (from the onset of the acoustic syllables) were computed. For each dependent variable, a repeated-measures ANOVA was performed with the modality $\left(A, V_{F}, V_{T}, A V_{F}\right.$, and $\left.A V_{T}\right)$ as the within-participant variable. For both analyses, the significance level was set at $p=.05$ and Greenhouse-Geisser corrected (for violation of the sphericity assumption) when appropriate. When required, post hoc analyses were conducted with Newman-Keuls tests.

\section{fMRI Analysis}

fMRI data were analyzed using the SPM8 software package (Wellcome Department of Imaging Neuroscience, Institute of Neurology, London, United Kingdom) running on MATLAB (The MathWorks, Natick, MA). Brainactivated regions were labeled using the SPM Anatomy toolbox (Eickhoff et al., 2005) and, if a brain region was not assigned or not specified in the SPM Anatomy toolbox, using the Talairach Daemon software (Lancaster et al., 2000). For visualization, activation maps were superimposed on a standard brain template using the MRICRON software (www.sph.sc.edu/comd/rorden/mricron/).

Data preprocessing steps for each participant included rigid realignment of functional images, coregistration of the structural image to the mean functional image, segmentation and normalization of the structural image to common subject space using the groupwise DARTEL registration method implemented in SPM8, warping of all realigned functional images using deformation flow fields generated from the normalization step, transformation into the Montreal Neurological Institute (MNI) space, and spatial smoothing using an 8-mm FWHM Gaussian kernel.

For individual analyses, neural activations related to the perceptual conditions were analyzed using a general linear model, including five regressors of interest $\left(A, V_{F}\right.$, $V_{T}, A V_{F}$, and $A V_{T}$ ) and the six realignment parameters, with the silent trials forming an implicit baseline. The BOLD response for each event was modeled using a single-bin finite impulse response basis function spanning the time of acquisition (3 sec). Before estimation, a high-pass filtering with a cutoff period of $128 \mathrm{sec}$ was applied. Beta weights associated with the modeled finite impulse responses were then computed to fit the observed BOLD signal time course in each voxel for each condition. Individual statistical maps were calculated for each perceptual condition with the related baseline and subsequently used for group statistics.

To draw population-based inferences, a second-level random effects group analysis was carried out with the modality $\left(A, V_{F}, V_{T}, A V_{F}\right.$, and $\left.A_{T}\right)$ as the within-participant variable and the participants treated as a random factor. 
First, for each modality, brain activity compared with the resting baseline was evaluated. Second, to determine common neural activity across modalities, several conjunction analyses were performed (i.e., $V_{F} \cap V_{T}, A V_{F} \cap$ $A V_{T}, A \cap V_{F} \cap A V_{F}, A \cap V_{T} \cap A V_{T}, A \cap V_{F} \cap V_{T} \cap A V_{F} \cap$ $A V_{T}$ ). Third, activity differences between visual conditions and between audiovisual conditions were evaluated (i.e., $V_{F}>V_{T}, V_{T}>V_{F}, A V_{F}>A V_{T}, A V_{T}>A V_{F}$ ). Fourth, to determine possible correlations between perceptual responses observed in the behavioral experiment and BOLD responses, covariate analyses were performed on the whole brain between neural activity in visual and audiovisual modalities (i.e., $\mathrm{V}_{\mathrm{F}}, \mathrm{AV}_{\mathrm{F}}, \mathrm{V}_{\mathrm{T}}$, $A V_{T}$ ) and visual identification scores as well as RTs related to visuo-lingual and visuo-facial speech movements $\left(\mathrm{V}_{\mathrm{F}}, \mathrm{V}_{\mathrm{T}}\right)$. In addition, brain regions showing higher or lower audiovisual responses compared with unimodal auditory and visual responses were identified using the $\max$ criterion test (i.e., $\left[\mathrm{AV}_{\mathrm{F}}>\mathrm{A}\right] \cap\left[\mathrm{AV}_{\mathrm{F}}>\mathrm{V}_{\mathrm{F}}\right],\left[\mathrm{AV}_{\mathrm{F}}<\right.$ $\mathrm{A}] \cap\left[\mathrm{AV}_{\mathrm{F}}<\mathrm{V}_{\mathrm{F}}\right],\left[\mathrm{AV}_{\mathrm{T}}>\mathrm{A}\right] \cap\left[\mathrm{AV}_{\mathrm{T}}>\mathrm{V}_{\mathrm{T}}\right],\left[\mathrm{AV}_{\mathrm{T}}<\mathrm{A}\right] \cap$ $\left[\mathrm{AV}_{\mathrm{T}}<\mathrm{V}_{\mathrm{T}}\right]$; see Stevenson et al., 2014). Modality, conjunction, and correlation contrasts were calculated with the significance level set at $p<.05$, family-wise error (FWE) corrected at the voxel level with a cluster extent of at least 20 voxels. All other contrasts were calculated with a significance level set at $p<.001$ uncorrected at the voxel level with a cluster extent of at least 20 voxels.

\section{RESULTS}

\section{Behavioral Results}

Overall, the mean proportion of correct responses was $82 \%$. The main effect of modality was significant $(F(4$, $52)=37.79, p<.001$ ), with more correct responses in the $\mathrm{A}, \mathrm{AV}_{\mathrm{F}}$, and $\mathrm{AV}_{\mathrm{T}}$ conditions than in the $\mathrm{V}_{\mathrm{F}}$ condition and in $\mathrm{V}_{\mathrm{F}}$ compared with $\mathrm{V}_{\mathrm{T}}$ conditions (on average, $\mathrm{A}=$ $98 \%, \mathrm{AV}_{\mathrm{F}}=98 \%, \mathrm{AV}_{\mathrm{T}}=95 \%, \mathrm{~V}_{\mathrm{F}}=70 \%, \mathrm{~V}_{\mathrm{T}}=49 \%$; all mentioned comparisons significant). The ANOVA on RTs demonstrated a significant effect of the modality $(F(4,52)=36.25, p<.001)$, with faster $\mathrm{RTs}_{\mathrm{T}}$ in $\mathrm{AV}_{\mathrm{F}}$ than in $\mathrm{V}_{\mathrm{F}}, \mathrm{A}, \mathrm{AV}_{\mathrm{T}}$, and $\mathrm{V}_{\mathrm{T}}$ conditions and slower $\mathrm{RT}$ s in $\mathrm{V}_{\mathrm{T}}$ than in the other conditions (on average, $\mathrm{AV}_{\mathrm{F}}=722 \mathrm{msec}, \mathrm{V}_{\mathrm{F}}=$ $774 \mathrm{msec}, \mathrm{A}=812 \mathrm{msec}, \mathrm{AV}_{\mathrm{T}}=913 \mathrm{msec}, \mathrm{V}_{\mathrm{T}}=1241 \mathrm{msec}$; all mentioned comparisons significant).

Importantly, despite slower RTs and lower recognition scores for visuo-lingual stimuli compared with visuo-facial

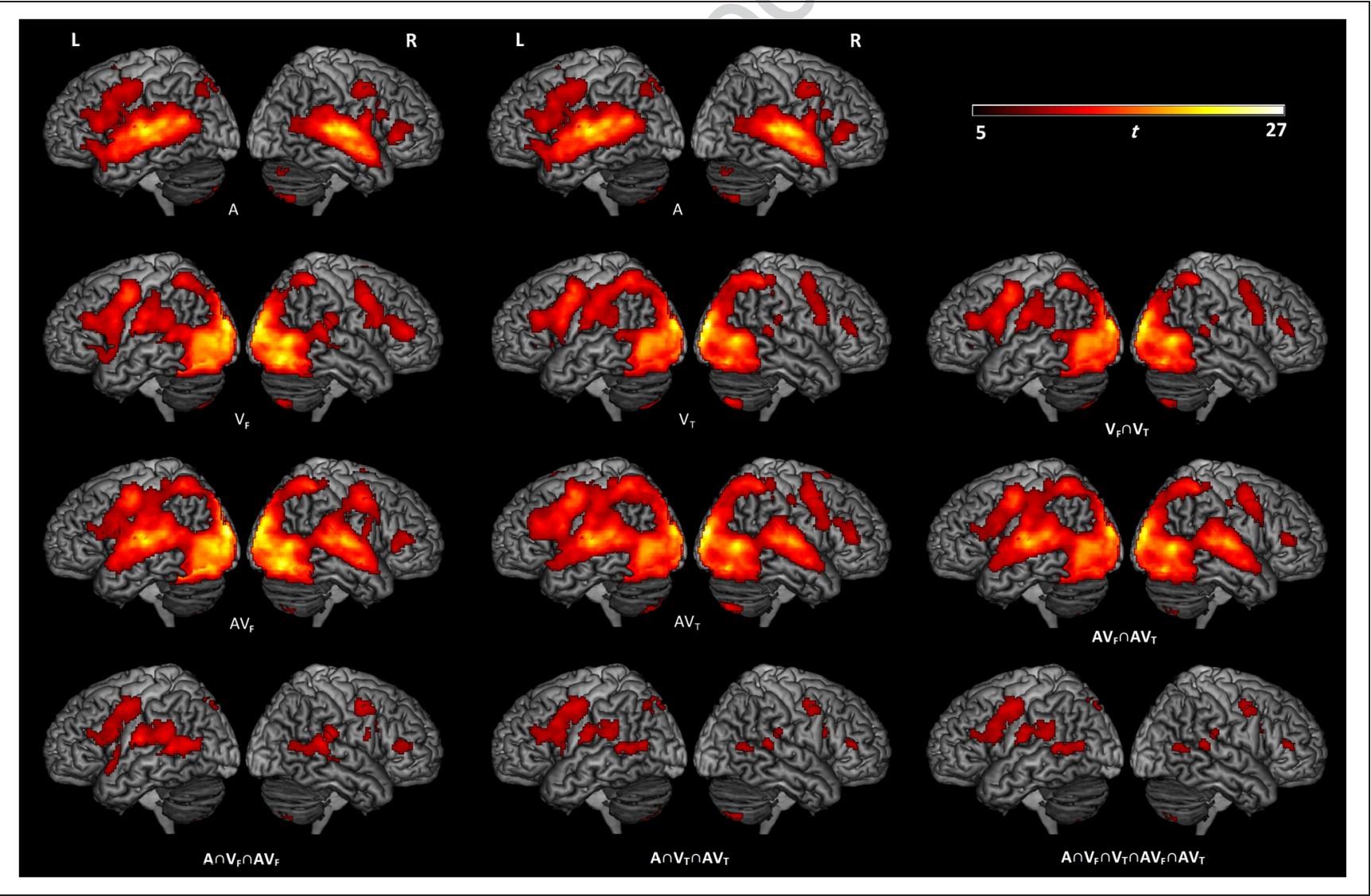

Figure 2. Surface rendering of brain regions activated in the auditory $(\mathrm{A})$, visuo-facial $\left(\mathrm{V}_{\mathrm{F}}\right)$, visuo-lingual $\left(\mathrm{V}_{\mathrm{T}}\right)$, audio-visuo-facial $\left(\mathrm{AV} \mathrm{V}_{\mathrm{F}}\right)$, and audio-visuo-lingual $\left(\mathrm{AV}_{\mathrm{T}}\right)$ conditions and showing overlapping activity between lip-related conditions (conjunction $\mathrm{A} \cap \mathrm{V}_{\mathrm{F}} \cap \mathrm{AV}_{\mathrm{F}}$ ), tongue-related conditions (conjunction $A \cap V_{T} \cap A V_{T}$ ), visual conditions (conjunction $V_{F} \cap V_{T}$ ), and audiovisual conditions (conjunction $A V_{F} \cap A V_{T}$ ) and between all modalities (conjunction $\mathrm{A} \cap \mathrm{V}_{\mathrm{F}} \cap \mathrm{V}_{\mathrm{T}} \cap \mathrm{AV}_{\mathrm{F}} \cap \mathrm{AV}_{\mathrm{T}} ; p<.05$, FWE corrected; cluster extent threshold of 20 voxels). 
stimuli (and to the other conditions), recognition scores for visuo-lingual stimuli remained above chance level (i.e., 49\% vs. 33\%). Interestingly, at the syllable level, individual differences were observed between facial and tongue visual recognition $\left(\mathrm{V}_{\mathrm{F}}: / \mathrm{pa} / 100 \%\right.$, /ta/ 64\%,
$/ \mathrm{ka} / 45 \% ; \mathrm{V}_{\mathrm{T}}: / \mathrm{pa} / 50 \%, / \mathrm{ta} / 50 \%, / \mathrm{ka} / 46 \% ;$ no statistical analyses were performed because of the small number of trials for each syllable). These differences suggest different categorization processes because of the nature of the stimuli.

Table 1. Maximum Activation Peak Summary and Contrast Estimates of Brain Regions Showing Overlapping Activity between All Conditions (Conjunction $\mathrm{A} \cap \mathrm{V}_{\mathrm{F}} \cap \mathrm{V}_{\mathrm{T}} \cap \mathrm{AV}_{\mathrm{F}} \cap \mathrm{AV}_{\mathrm{T}} ; p<.05$, FWE Corrected, Cluster Extent Threshold of 20 Voxels)

\begin{tabular}{|c|c|c|c|c|c|c|c|c|c|c|c|}
\hline \multirow[b]{2}{*}{ Regions } & \multirow[b]{2}{*}{$B A$} & \multirow[b]{2}{*}{$H$} & \multicolumn{3}{|c|}{ MNI Coordinates } & \multirow[b]{2}{*}{$t$} & \multicolumn{5}{|c|}{ Contrast Estimates } \\
\hline & & & $x$ & $y$ & $z$ & & $A$ & $V_{F}$ & $V_{T}$ & $A V_{F}$ & $A V_{T}$ \\
\hline \multicolumn{12}{|l|}{ Auditory Cortex } \\
\hline STG & 22 & $\mathrm{~L}$ & -50 & -44 & 8 & 8.16 & 0.12 & 0.11 & 0.09 & 0.12 & 0.14 \\
\hline Middle temporal gyrus & 39 & $\mathrm{~L}$ & -58 & -56 & 6 & 7.23 & 0.12 & 0.13 & 0.10 & 0.11 & 0.13 \\
\hline Middle temporal gyrus & 39 & $\mathrm{R}$ & 58 & -62 & 8 & 6.63 & 0.08 & 0.14 & 0.13 & 0.15 & 0.13 \\
\hline STG & 22 & $\mathrm{R}$ & 54 & -60 & 12 & 6.39 & 0.10 & 0.14 & 0.11 & 0.14 & 0.14 \\
\hline Heschl's gyrus & 42 & $\mathrm{R}$ & 56 & -38 & 12 & & 0.15 & 0.14 & 0.12 & 0.17 & 0.17 \\
\hline \multicolumn{12}{|l|}{ Parietal Cortex } \\
\hline Parietal operculum (OP4) & $40 / 43$ & $\mathrm{~L}$ & -64 & , & 16 & 8.32 & 0.13 & 0.10 & 0.07 & 0.13 & 0.13 \\
\hline Parietal operculum (OP1) & $40 / 43$ & $\mathrm{~L}$ & -58 & 10 & 22 & 8.14 & 0.09 & 0.11 & 0.09 & 0.11 & 0.11 \\
\hline Inferior parietal lobule & 40 & $\mathrm{~L}$ & -60 & & 20 & 7.77 & 0.19 & 0.14 & 0.12 & 0.21 & 0.20 \\
\hline Inferior parietal lobule & 40 & $\mathrm{R}$ & & -28 & 22 & 7.03 & 0.14 & 0.13 & 0.10 & 0.19 & 0.17 \\
\hline \multicolumn{12}{|l|}{ Motor Cortex } \\
\hline Primary motor cortex & 4 & $\mathrm{~L}$ & -54 & -6 & 46 & 9.08 & 0.14 & 0.20 & 0.18 & 0.21 & 0.22 \\
\hline Premotor cortex & 6 & $\mathrm{~L}$ & -52 & 2 & 44 & 8.60 & 0.14 & 0.18 & 0.20 & 0.18 & 0.21 \\
\hline Insula & 13 & $\mathrm{~L}$ & -36 & 10 & 24 & 8.50 & 0.12 & 0.15 & 0.13 & 0.13 & 0.15 \\
\hline Middle frontal gyrus & 9 & $\mathrm{~L}$ & -44 & 12 & 28 & 8.26 & 0.19 & 0.23 & 0.23 & 0.19 & 0.25 \\
\hline \multicolumn{12}{|l|}{$p F C$} \\
\hline Inferior frontal gyrus (pars triangularis) & 45 & $\mathrm{~L}$ & -52 & 30 & 24 & 6.49 & 0.08 & 0.12 & 0.13 & 0.08 & 0.13 \\
\hline Inferior frontal gyrus (pars opercularis) & 44 & $\mathrm{~L}$ & -58 & 8 & 32 & 6.69 & 0.09 & 0.12 & 0.15 & 0.10 & 0.11 \\
\hline Inferior frontal gyrus (pars triangularis) & 45 & $\mathrm{R}$ & 54 & 36 & 12 & 7.07 & 0.09 & 0.12 & 0.10 & 0.10 & 0.11 \\
\hline Superior frontal gyrus & 6 & $\mathrm{~L}$ & -6 & 4 & 60 & 8.91 & 0.12 & 0.13 & 0.13 & 0.12 & 0.12 \\
\hline Middle frontal gyrus & 9 & $\mathrm{R}$ & 56 & 2 & 44 & 7.20 & 0.11 & 0.13 & 0.10 & 0.16 & 0.12 \\
\hline Middle frontal gyrus & 9 & $\mathrm{R}$ & 36 & 8 & 24 & 7.16 & 0.09 & 0.11 & 0.09 & 0.09 & 0.11 \\
\hline \multicolumn{12}{|l|}{ Other Regions } \\
\hline Associative visual cortex & V5 & $\mathrm{L}$ & -54 & -66 & 10 & 7.87 & 0.10 & 0.15 & 0.12 & 0.16 & 0.14 \\
\hline Precuneus & 7 & $\mathrm{~L}$ & -8 & -78 & 46 & 8.46 & 0.27 & 0.36 & 0.35 & 0.39 & 0.41 \\
\hline Cerebellum (VIIb) & & $\mathrm{R}$ & 16 & -74 & -50 & 8.05 & 0.06 & 0.06 & 0.08 & 0.06 & 0.08 \\
\hline Anterior cingulate gyrus & 32 & $\mathrm{~L}$ & -4 & 16 & 42 & T6.41 & 0.12 & 0.16 & 0.18 & 0.12 & 0.14 \\
\hline
\end{tabular}




\section{fMRI Results: Modality and Conjunction Analyses}

Brain activity compared with the resting baseline in each modality $\left(\mathrm{A}, \mathrm{V}_{\mathrm{F}}, \mathrm{V}_{\mathrm{T}}, \mathrm{AV}_{\mathrm{F}}\right.$, and $\left.\mathrm{AV}_{\mathrm{T}}\right)$ as well as conjunction analyses (i.e., $\mathrm{V}_{\mathrm{F}} \cap \mathrm{V}_{\mathrm{T}}, \mathrm{AV}_{\mathrm{F}} \cap \mathrm{AV} \mathrm{V}_{\mathrm{T}}, \mathrm{A} \cap \mathrm{V}_{\mathrm{F}} \cap \mathrm{AV} \mathrm{V}_{\mathrm{F}}, \mathrm{A} \cap \mathrm{V}_{\mathrm{T}} \cap$ $\left.\mathrm{AV}_{\mathrm{T}}, \mathrm{A} \cap \mathrm{V}_{\mathrm{F}} \cap \mathrm{V}_{\mathrm{T}} \cap \mathrm{AV}_{\mathrm{F}} \cap \mathrm{AV}_{\mathrm{T}}\right)$ are displayed in Figure 2 . Globally, bilateral activity of auditory regions (including primary, secondary, and associative areas in the STG and extending to the middle temporal gyrus) as well as strong premotor activations (extending to the inferior frontal gyrus and left primary motor cortex) were observed in A condition (see Figure 2, Condition A). In both $V_{F}$ and $V_{T}$ conditions, visual (bilateral primary and associative regions, including V5), auditory (pSTS and pSTG), and motor (bilateral primary motor and premotor cortices as well as inferior frontal gyri) activities were observed (see Figure 2, Conditions $V_{F}$ and $V_{T}$ as well as conjunction $V_{T} \cap V_{F}$ ). Activities in $\mathrm{AV}_{\mathrm{F}}$ and $\mathrm{AV}_{\mathrm{T}}$ conditions were mainly found in primary and associative auditory and visual regions and in motor and frontal cortices (see Figure 2, Conditions $\mathrm{AV}_{\mathrm{F}}$ and $\mathrm{AV}_{\mathrm{T}}$ as well as conjunction $\mathrm{AV}_{\mathrm{F}} \cap \mathrm{AV}_{\mathrm{T}}$ ).

Importantly, common activations in all five conditions (see Table 1 and Figure 2, conjunction $A \cap V_{F} \cap V_{T} \cap A V_{F} \cap$ $A V_{T}$ ) were observed in the pSTS, bilaterally extending to the adjacent posterior middle temporal gyrus and left V5. Additional auditory activity was also observed bilaterally in the posterior temporal gyrus, extending to the right secondary auditory cortex, the parietal operculum, and the antero-ventral part of the inferior parietal lobule. Interestingly, strong premotor activity was also observed, mainly in the left hemisphere, and also including activity in the opercular part of the left inferior frontal gyrus, the triangular part of the inferior frontal gyrus, the left anterior IC, and the left primary motor cortex. Finally, additional activity was also observed in the ACC, the left precuneus, and the right cerebellum (Lobule VII).

In summary, apart from sensory-specific activity in auditory and visual conditions, our results demonstrate a shared neural network involved in all conditions, mainly including multisensory activity around the pSTS and the pSTG ex- tending to adjacent inferior parietal regions as well as the premotor cortex extending to inferior frontal regions.

\section{fMRI Results: Modality Differences}

$V_{F}>V_{T}$

Several auditory regions were more activated during visuo-facial than during visuo-lingual perception, with stronger bilateral activation of the posterior temporal gyrus/sulcus, extending to the middle temporal gyrus. Stronger activation of the left anterior temporal gyrus (temporopolar area) and the right primary auditory cortex was also observed. Large parts of the primary and associative visual areas were also more activated (V1, V2, V3, and V4), extending to the fusiform gyrus. In addition, stronger frontal activity was observed in the right pars triangularis and middle frontal gyrus, the left pars orbitalis, and the left anterior IC. Finally, stronger additional activity was also observed in the right BG in the lentiform nucleus and the left precuneus (see Figure 3 and Table 2).

$V_{T}>V_{F}$

Bilateral premotor dorsal regions were more activated during visuo-lingual perception than during visuo-facial perception. Interestingly, stronger activity was observed in the primary somatosensory cortices, extending to the adjacent parts of the dorsal inferior parietal lobule and intraparietal sulcus. Stronger bilateral visual activity was also observed, including primary and associative visual areas (V1 and V2). Finally, stronger additional activity was also observed in the right precuneus, the posterior cingulate cortex, and the middle part of the right parahippocampal gyrus.

$A V_{F}>A V_{T}$

Audio-visuo-facial stimuli, compared with audio-visuolingual stimuli, induced stronger bilateral activation of the
Figure 3. Surface rendering of brain regions activated showing significant change in activity between visual conditions related to lip and tongue movements $\left(\mathrm{V}_{\mathrm{F}}>\mathrm{V}_{\mathrm{T}}\right.$ and $\mathrm{V}_{\mathrm{T}}>\mathrm{V}_{\mathrm{F}}$ ) and audiovisual conditions related to lip and tongue movements $\left(\mathrm{AV}_{\mathrm{F}}>\mathrm{AV}_{\mathrm{T}}\right.$ and $\mathrm{AV}_{\mathrm{T}}>\mathrm{AV}_{\mathrm{F}}$; $p<.001$ uncorrected; cluster extend threshold of 20 voxels).

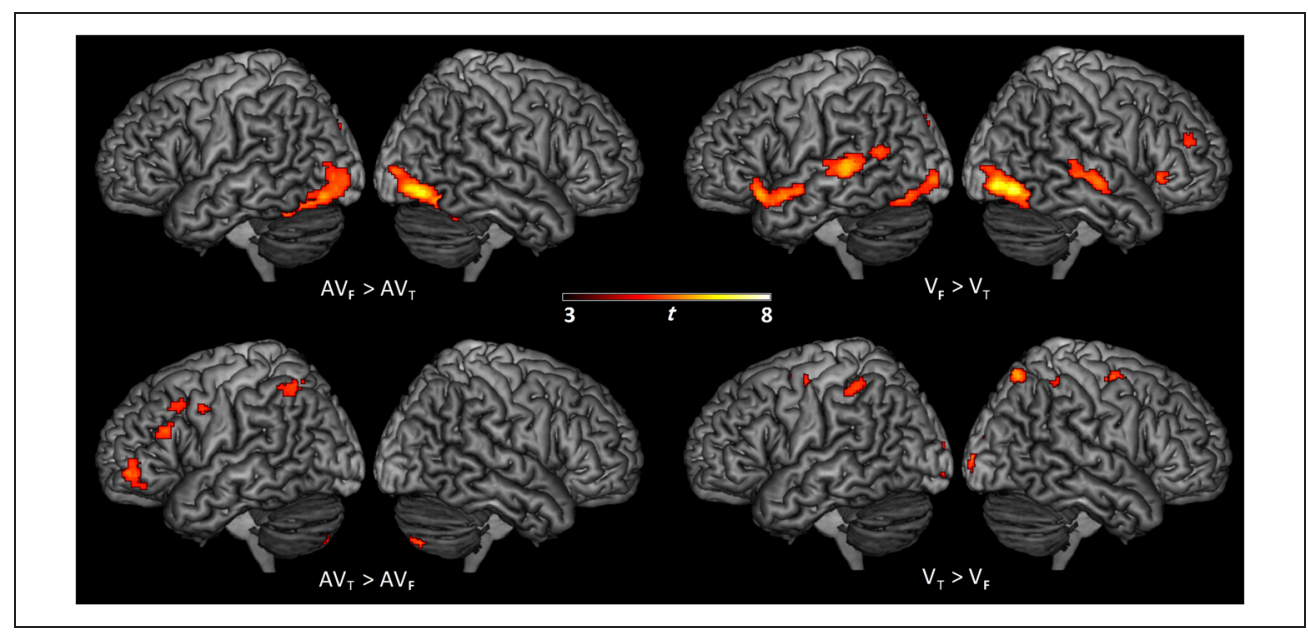


Table 2. Maximum Activation Peaks and Contrast Estimates of Brain Regions Showing Significant Change in Activity between VisuoFacial and Visuo-Lingual Conditions ( $\mathrm{A}: \mathrm{V}_{\mathrm{F}}>\mathrm{V}_{\mathrm{T}} ; \mathrm{B}: \mathrm{V}_{\mathrm{T}}>\mathrm{V}_{\mathrm{F}} ; p<.001$ Uncorrected, Cluster Extend Threshold of 20 Voxels) and between Audio-Visuo-Facial and Audio-Visuo-Lingual Conditions $\left(\mathrm{C}: \mathrm{AV}_{\mathrm{F}}>\mathrm{AV}_{\mathrm{T}} ; \mathrm{D}: \mathrm{AV}_{\mathrm{T}}>\mathrm{AV}_{\mathrm{F}} ; p<.001\right.$ Uncorrected, Cluster Extend Threshold of 20 Voxels)

\begin{tabular}{|c|c|c|c|c|c|c|c|c|c|c|c|}
\hline \multirow[b]{2}{*}{ Regions } & \multirow[b]{2}{*}{$B A$} & \multirow[b]{2}{*}{$H$} & \multicolumn{3}{|c|}{ MNI Coordinates } & \multirow[b]{2}{*}{$t$} & \multicolumn{5}{|c|}{ Contrast Estimates } \\
\hline & & & $x$ & $y$ & $z$ & & $A$ & $V_{F}$ & $V_{T}$ & $A V_{F}$ & $A V_{T}$ \\
\hline \multicolumn{12}{|l|}{ A. $V F>V T$} \\
\hline \multicolumn{12}{|l|}{ Auditory cortex } \\
\hline STG & 22 & $\mathrm{~L}$ & -64 & -34 & 4 & 5.38 & 0.17 & 0.05 & -0.02 & 0.10 & 0.12 \\
\hline STG & 22 & $\mathrm{~L}$ & -60 & -56 & 14 & 4.28 & 0.14 & 0.09 & 0.04 & 0.09 & 0.09 \\
\hline Heschl's gyrus & 42 & $\mathrm{R}$ & 62 & -32 & 8 & 3.85 & 0.20 & 0.06 & 0.01 & 0.16 & 0.15 \\
\hline STG & 22 & $\mathrm{R}$ & 44 & -22 & -6 & 5.02 & 0.08 & 0.03 & -0.02 & 0.05 & 0.05 \\
\hline Middle temporal gyrus & 21 & $\mathrm{R}$ & 60 & -14 & -6 & 4.60 & 0.21 & 0.04 & -0.04 & 0.14 & 0.14 \\
\hline Middle temporal gyrus & 21 & $\mathrm{~L}$ & -54 & 6 & -16 & 4.82 & 0.11 & 0.03 & -0.03 & 0.08 & 0.05 \\
\hline Temporopolar area & 38 & $\mathrm{~L}$ & -50 & -2 & -12 & 4.39 & 0.10 & 0.02 & -0.03 & 0.07 & 0.07 \\
\hline \multicolumn{12}{|l|}{ Frontal cortex } \\
\hline Inferior frontal gyrus (pars orbitalis) & 47 & $\mathrm{~L}$ & -40 & 22 & -14 & 5.29 & 0.10 & 0.06 & -0.02 & 0.07 & 0.05 \\
\hline Inferior frontal gyrus (pars triangularis) & 45 & $\mathrm{R}$ & 54 & 24 & 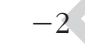 & 4.26 & 0.06 & 0.01 & -0.04 & 0.03 & 0.01 \\
\hline Middle frontal gyrus & 10 & $\mathrm{R}$ & 38 & 44 & 20 & 3.82 & 0.04 & 0.03 & -0.02 & 0.01 & 0.02 \\
\hline Insula & 13 & $\mathrm{~L}$ & -38 & 0 & & 3.72 & 0.08 & 0.06 & 0.00 & 0.08 & 0.06 \\
\hline \multicolumn{12}{|l|}{ Visual cortex } \\
\hline Primary visual cortex (V1) & 17 & $\mathrm{~L}$ & -6 & & 8 & 5.93 & 0.04 & 0.41 & 0.23 & 0.47 & 0.24 \\
\hline Associative visual cortex (V2) & 18 & $\mathrm{~L}$ & & & -4 & 4.65 & 0.00 & 0.23 & 0.16 & 0.23 & 0.16 \\
\hline Associative visual cortex (V3) & 19 & $\mathrm{~L}$ & & -76 & -4 & 5.37 & 0.01 & 0.27 & 0.13 & 0.32 & 0.14 \\
\hline Associative visual cortex (V4) & 19 & $\mathrm{~L}$ & -34 & -78 & -14 & 4.30 & 0.01 & 0.29 & 0.20 & 0.29 & 0.19 \\
\hline Fusiform gyrus & 37 & $\mathrm{~L}$ & -28 & -72 & -16 & 4.42 & 0.03 & 0.41 & 0.30 & 0.44 & 0.30 \\
\hline Primary visual cortex (V1) & 17 & $\mathrm{R}$ & 10 & -70 & 12 & 6.38 & 0.07 & 0.41 & 0.24 & 0.48 & 0.25 \\
\hline Associative visual cortex (V2) & 18 & $\mathrm{R}$ & 22 & -60 & 8 & 6.89 & 0.09 & 0.28 & 0.15 & 0.33 & 0.19 \\
\hline Associative visual cortex (V3) & 19 & $\mathrm{R}$ & 34 & -92 & 4 & 3.72 & 0.02 & 0.24 & 0.18 & 0.24 & 0.16 \\
\hline Associative visual cortex (V4) & 19 & $\mathrm{R}$ & 40 & -72 & -10 & 7.31 & -0.01 & 0.22 & 0.13 & 0.23 & 0.13 \\
\hline Fusiform gyrus & 37 & $\mathrm{R}$ & 38 & -50 & -16 & 5.12 & 0.02 & 0.23 & 0.15 & 0.23 & 0.14 \\
\hline \multicolumn{12}{|l|}{ Other regions } \\
\hline Lentiform nucleus & & $\mathrm{R}$ & 30 & -20 & -4 & 5.46 & 0.03 & 0.02 & -0.03 & 0.02 & 0.03 \\
\hline Precuneus & 7 & $\mathrm{~L}$ & -2 & -82 & 36 & 4.65 & 0.13 & 0.39 & 0.19 & 0.42 & 0.24 \\
\hline
\end{tabular}

B. $V T>V F$

Motor regions

Premotor cortex

Premotor cortex

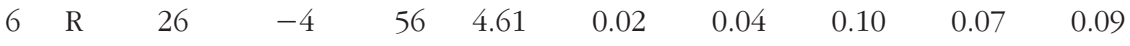

Parietal lobule

Inferior parietal lobule

$\begin{array}{llll}6 & \mathrm{~L} & -24 & -6\end{array}$

$54 \quad 4.14$

$0.04 \quad 0.05$

$0.13 \quad 0.05$

0.14

Primary somatosensory cortex

\begin{tabular}{rrrrrrrrrrr}
40 & $\mathrm{~L}$ & -44 & -40 & 50 & 4.03 & 0.07 & 0.10 & 0.20 & 0.15 & 0.22 \\
2 & $\mathrm{~L}$ & -40 & -42 & 52 & 3.82 & 0.06 & 0.10 & 0.20 & 0.15 & 0.23 \\
\hline
\end{tabular}


Table 2. (continued)

\begin{tabular}{|c|c|c|c|c|c|c|c|c|c|c|c|}
\hline \multirow[b]{2}{*}{ Regions } & \multirow[b]{2}{*}{$B A$} & \multirow[b]{2}{*}{$H$} & \multicolumn{3}{|c|}{ MNI Coordinates } & \multirow[b]{2}{*}{$t$} & \multicolumn{5}{|c|}{ Contrast Estimates } \\
\hline & & & $x$ & $y$ & $z$ & & $A$ & $V_{F}$ & $V_{T}$ & $A V_{F}$ & $A V_{T}$ \\
\hline Intraparietal sulcus & & $\mathrm{R}$ & 30 & -40 & 40 & 4.32 & 0.01 & 0.04 & 0.10 & 0.06 & 0.07 \\
\hline Primary somatosensory cortex & 2 & $\mathrm{R}$ & 34 & -42 & 50 & 3.65 & 0.02 & 0.11 & 0.19 & 0.15 & 0.18 \\
\hline Primary somatosensory cortex & 3 & $\mathrm{R}$ & 32 & -32 & 42 & 3.54 & 0.01 & 0.05 & 0.09 & 0.07 & 0.08 \\
\hline Superior parietal lobule & 7 & $\mathrm{R}$ & 24 & -68 & 58 & 5.20 & 0.08 & 0.09 & 0.23 & 0.17 & 0.23 \\
\hline \multicolumn{12}{|l|}{ Visual regions } \\
\hline Primary visual cortex (V1) & 17 & $\mathrm{~L}$ & 0 & -94 & 0 & 5.30 & 0.03 & 0.42 & 0.59 & 0.47 & 0.59 \\
\hline Associative visual cortex (V2) & 18 & $\mathrm{~L}$ & -4 & -98 & 10 & 4.89 & -0.01 & 0.22 & 0.31 & 0.25 & 0.30 \\
\hline Primary visual cortex (V1) & 17 & $\mathrm{R}$ & 14 & -94 & 4 & 5.86 & 0.03 & 0.36 & 0.49 & 0.38 & 0.47 \\
\hline Associative visual cortex (V2) & 18 & $\mathrm{R}$ & 8 & -86 & -10 & 4.61 & 0.04 & 0.31 & 0.40 & 0.34 & 0.39 \\
\hline \multicolumn{12}{|l|}{ Other regions } \\
\hline Posterior cingulate cortex & 31 & $\mathrm{~L}$ & -16 & -60 & 22 & 5.05 & 0.04 & 0.02 & 0.11 & 0.04 & 0.06 \\
\hline Posterior cingulate cortex & 31 & $\mathrm{R}$ & 18 & -58 & 22 & 3.80 & & 0.03 & 0.12 & 0.05 & 0.06 \\
\hline Parahippocampal gyrus & 36 & $\mathrm{R}$ & 26 & -38 & -16 & 4.33 & -0.03 & 0.00 & 0.09 & 0.05 & 0.04 \\
\hline
\end{tabular}

C. $A V F>A V T$

Visual cortex

Associative visual cortex (V2)

Primary visual cortex (V1)

Associative visual cortex (V3)

Superior parietal lobule (cuneus)

Primary visual cortex (V1)

Associative visual cortex (V2)

Associative visual cortex (V4)

$\begin{array}{rrrrrrrrrrr}18 & \mathrm{~L} & -2 & -74 & 10 & 6.76 & 0.05 & 0.41 & 0.24 & 0.46 & 0.24 \\ 17 & \mathrm{~L} & -8 & -76 & 10 & 6.65 & 0.05 & 0.38 & 0.22 & 0.43 & 0.22 \\ 19 & \mathrm{~L} & -12 & -88 & 34 & 4.13 & 0.07 & 0.32 & 0.24 & 0.35 & 0.25 \\ 7 & \mathrm{~L} & -2 & -84 & 36 & 3.82 & 0.12 & 0.38 & 0.21 & 0.41 & 0.24 \\ 17 & \mathrm{R} & 10 & -72 & 12 & 7.89 & 0.06 & 0.41 & 0.25 & 0.49 & 0.25 \\ 18 & \mathrm{R} & 20 & -62 & 8 & 7.07 & 0.09 & 0.28 & 0.16 & 0.34 & 0.19 \\ 19 & \mathrm{R} & 40 & -72 & -10 & 6.54 & -0.01 & 0.22 & 0.13 & 0.23 & 0.13\end{array}$

Other regions

Amygdala

Amygdala

Posterior cingulate cortex

Frontopolar area (Fp2)

Temporopolar area

$\begin{array}{rrrrrrrrrrr} & \mathrm{L} & -18 & -6 & -14 & 4.26 & 0.08 & 0.10 & 0.05 & 0.10 & 0.02 \\ & \mathrm{R} & 22 & -4 & -14 & 3.90 & 0.06 & 0.05 & 0.02 & 0.09 & 0.02 \\ 31 & \mathrm{R} & 16 & -34 & 42 & 3.73 & 0.00 & 0.00 & -0.01 & 0.04 & -0.03 \\ 10 & \mathrm{R} & 4 & 54 & -10 & 3.95 & 0.05 & -0.03 & -0.07 & 0.03 & -0.07 \\ 38 & \mathrm{R} & 32 & 4 & -20 & 4.23 & 0.13 & 0.05 & 0.03 & 0.14 & 0.05\end{array}$

D. $A V T>A V F$

Parietal cortex

Inferior parietal lobule

$\begin{array}{lllllllllll}40 & \mathrm{~L} & -44 & -62 & 54 & 3.91 & 0.02 & -0.02 & -0.01 & -0.04 & 0.04\end{array}$ $\mathrm{pFC}$

Premotor cortex

Middle frontal gyrus

Middle frontal gyrus

Dorsolateral pFC

\begin{tabular}{rrrrrrrrrrr}
6 & $\mathrm{~L}$ & -42 & 0 & 36 & 3.71 & 0.10 & 0.17 & 0.18 & 0.10 & 0.19 \\
9 & $\mathrm{~L}$ & -38 & 2 & 36 & 3.78 & 0.11 & 0.15 & 0.17 & 0.10 & 0.18 \\
8 & $\mathrm{~L}$ & -52 & 16 & 42 & 3.63 & 0.11 & 0.03 & 0.02 & 0.01 & 0.10 \\
46 & $\mathrm{~L}$ & -46 & 26 & 24 & 4.25 & 0.07 & 0.10 & 0.11 & 0.05 & 0.12 \\
\hline
\end{tabular}


Table 2. (continued)

\begin{tabular}{|c|c|c|c|c|c|c|c|c|c|c|c|}
\hline \multirow[b]{2}{*}{ Regions } & \multirow[b]{2}{*}{$B A$} & \multirow[b]{2}{*}{$H$} & \multicolumn{3}{|c|}{ MNI Coordinates } & \multirow[b]{2}{*}{$t$} & \multicolumn{5}{|c|}{ Contrast Estimates } \\
\hline & & & $x$ & $y$ & $z$ & & $A$ & $V_{F}$ & $V_{T}$ & $A V_{F}$ & $A V_{T}$ \\
\hline Dorsolateral pFC & 10 & $\mathrm{~L}$ & -36 & 50 & -4 & 4.39 & 0.05 & 0.02 & 0.04 & -0.01 & 0.05 \\
\hline Dorsolateral pFC & 11 & $\mathrm{~L}$ & -36 & 46 & -6 & 4.30 & 0.04 & 0.01 & 0.02 & -0.01 & 0.04 \\
\hline \multicolumn{12}{|l|}{ Other regions } \\
\hline Primary visual cortex (V1) & 17 & $\mathrm{~L}$ & -8 & -100 & 2 & 4.25 & 0.02 & 0.26 & 0.33 & 0.24 & 0.33 \\
\hline Cerebellum (VIIb) & & $\mathrm{R}$ & 20 & -76 & -48 & 4.35 & 0.05 & 0.06 & 0.08 & 0.03 & 0.09 \\
\hline ACC & 32 & $\mathrm{~L}$ & -22 & 42 & 4 & 3.69 & 0.00 & -0.02 & -0.01 & -0.02 & 0.01 \\
\hline
\end{tabular}

primary and associative visual areas (V1, V2, V3, and V4). Stronger activity was also observed in the amygdala and the right posterior cingulate gyrus as well as in the right temporopolar and frontopolar areas.

$A V_{T}>A V_{F}$

Audio-visuo-lingual stimuli, compared with audio-visuofacial stimuli, induced stronger activation of the left premotor cortex, extending to the adjacent middle and inferior frontal gyri, and the left dorsal inferior parietal lobule, extending to the intraparietal sulcus. Stronger additional activity was also observed in the left dorsolateral $\mathrm{pFC}$, the left primary visual cortex, the right cerebellum (Lobule VII), and the left ACC.

To summarize, seeing tongue-related stimuli globally induced stronger motor and somatosensory activity, whereas auditory and visual cortices were globally more activated during lip-related stimuli presentation.

\section{fMRI Results: Correlation between Visual Recognition Scores and Neural Activity}

For tongue-related stimuli, the covariance analysis between visual recognition scores in the behavioral ex- periment and BOLD activity observed in $V_{T}$ and $A V_{T}$ conditions in the fMRI experiment demonstrated a significant correlation in the left dorsal part of the premotor cortex (see Figure 4 and Table 3).

For lip-related stimuli, a significant correlation was observed between visual recognition scores and neural responses in the $\mathrm{V}_{\mathrm{F}}$ condition in the right primary, secondary, and associative (MT/V5) visual regions and in the right fusiform gyrus. Similarly, a significant correlation in the $\mathrm{AV}_{\mathrm{F}}$ condition was observed in the bilateral associative visual cortex, in the left fusiform gyrus, in the lingual gyrus, in the left cerebellum, and in the parahippocampal gyrus.

To summarize, a correlation between visual recognition scores and neural activity was observed in the left premotor cortex for tongue-related stimuli and in visual regions for lip-related stimuli.

\section{fMRI Results: Correlation between Visual RTs and Neural Activity}

For both lip- and tongue-related stimuli, the covariance analysis between RTs observed for unimodal visual stimuli in the behavioral experiment and BOLD activity observed in visual and audiovisual conditions in the fMRI
Figure 4. Surface rendering of brain regions activated showing correlation between visual recognition scores and neural activity in the audio-visuo-facial $\left(\mathrm{AV}_{\mathrm{F}}\right)$, audio-visuo-lingual $\left(\mathrm{AV}_{\mathrm{T}}\right)$, visuo-facial $\left(\mathrm{V}_{\mathrm{F}}\right)$, and visuolingual $\left(\mathrm{V}_{\mathrm{T}}\right)$ conditions $(p<.05$, FWE corrected; cluster extent threshold of 20 voxels).

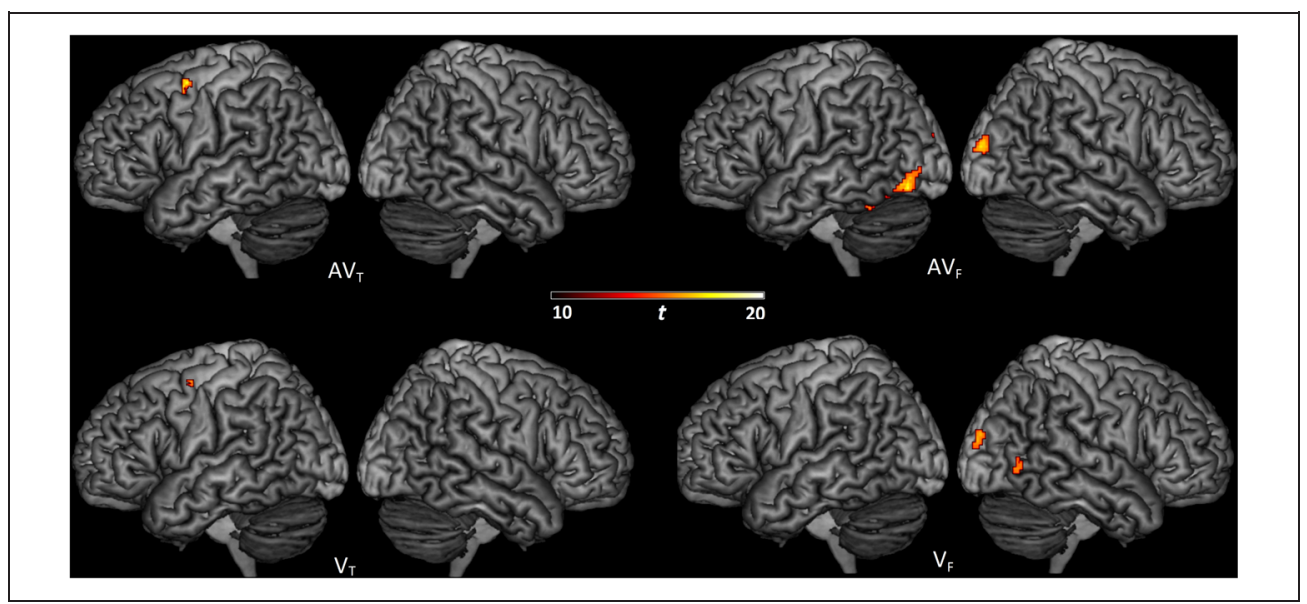


Table 3. Maximum Activation Peaks Showing Correlation between Visual Recognition Scores and Neural Activity in the (A) VisuoLingual $\left(\mathrm{V}_{\mathrm{T}}\right),(\mathrm{B})$ Audio-Visuo-Lingual $\left(\mathrm{AV}_{\mathrm{T}}\right),(\mathrm{C})$ Visuo-Facial $\left(\mathrm{V}_{\mathrm{F}}\right)$, and (D) Audio-Visuo-Facial Conditions $\left(\mathrm{AV}_{\mathrm{F}} ; p<.05\right.$, FWE Corrected, Cluster Extent Threshold of 20 Voxels)

\begin{tabular}{|c|c|c|c|c|c|c|}
\hline \multirow[b]{2}{*}{ Regions } & \multirow[b]{2}{*}{$B A$} & \multirow[b]{2}{*}{$H$} & \multicolumn{3}{|c|}{ MNI Coordinates } & \multirow[b]{2}{*}{$t$} \\
\hline & & & $x$ & $y$ & $z$ & \\
\hline \multicolumn{7}{|l|}{ A. $V_{T}$} \\
\hline Premotor cortex & 6 & $\mathrm{~L}$ & -34 & -4 & 54 & 16.65 \\
\hline \multicolumn{7}{|l|}{ B. $A V_{T}$} \\
\hline Premotor cortex & 6 & $\mathrm{~L}$ & -34 & 0 & 54 & 16.34 \\
\hline \multicolumn{7}{|l|}{ C. $V_{F}$} \\
\hline \multicolumn{7}{|l|}{ Visual cortex } \\
\hline $\begin{array}{l}\text { Associative visual } \\
\text { cortex (MT/V5) }\end{array}$ & 19 & $\mathrm{R}$ & 44 & -64 & 0 & 11.21 \\
\hline $\begin{array}{l}\text { Primary visual } \\
\text { cortex (V1) }\end{array}$ & 17 & $\mathrm{R}$ & 22 & -60 & 2 & 12.21 \\
\hline $\begin{array}{l}\text { Associative visual } \\
\text { cortex (V2) }\end{array}$ & 18 & $\mathrm{R}$ & 22 & -90 & 20 & 12.75 \\
\hline Fusiform gyrus & 37 & $\mathrm{R}$ & 52 & -68 & -2 & 11.82 \\
\hline \multicolumn{7}{|l|}{ D. $A V_{F}$} \\
\hline \multicolumn{7}{|l|}{ Visual cortex } \\
\hline Fusiform gyrus & 37 & $\mathrm{~L}$ & -36 & -50 & & 19.54 \\
\hline $\begin{array}{l}\text { Associative visual } \\
\text { cortex (V3) }\end{array}$ & 19 & $\mathrm{~L}$ & -34 & 76 & -12 & 17.19 \\
\hline $\begin{array}{l}\text { Associative visual } \\
\text { cortex (V2) }\end{array}$ & 18 & $\mathrm{R}$ & 22 & & 14 & 14.57 \\
\hline $\begin{array}{l}\text { Associative visual } \\
\text { cortex (V2) }\end{array}$ & 18 & $\mathrm{~L}$ & & -88 & 22 & 14.96 \\
\hline $\begin{array}{l}\text { Associative visual } \\
\text { cortex (V3) }\end{array}$ & 19 & $\mathrm{R}$ & 22 & -66 & -10 & 12.03 \\
\hline Lingual gyrus & 18 & $\mathrm{R}$ & 8 & -74 & -8 & 13.14 \\
\hline \multicolumn{7}{|l|}{ Other regions } \\
\hline Culmen & & $\mathrm{L}$ & -14 & -48 & -6 & 18.82 \\
\hline Declive & & $\mathrm{L}$ & -30 & -58 & -16 & 13.54 \\
\hline $\begin{array}{l}\text { Parahippocampal } \\
\text { gyrus }\end{array}$ & 19 & $\mathrm{~L}$ & -20 & -56 & -10 & 13.93 \\
\hline
\end{tabular}

experiment demonstrated a significant correlation in visual regions (including the primary and associative visual brain areas and the fusiform gyrus). Other correlational activity was found in the superior parietal lobule and adjacent intraparietal sulcus for $\mathrm{V}_{\mathrm{T}}, \mathrm{V}_{\mathrm{F}}$, and $\mathrm{AV}_{\mathrm{F}}$ condi- tions as well as in the left premotor cortex for $\mathrm{V}_{\mathrm{F}}$ (see Figure 5 and Table 4).

To summarize, a correlation between RTs and neural activity was mainly observed in visual and superior parietal regions for both tongue- and lip-related stimuli.

\section{fMRI Results: Different Audiovisual Neural Responses Compared with Auditory and Visual Modalities}

Higher neural responses were only found for audiovisuo-facial stimuli (see Figure 6 , condition $\left[\mathrm{AV}_{\mathrm{F}}>\mathrm{A}\right] \cap$ $\left.\left[\mathrm{AV}_{\mathrm{F}}>\mathrm{V}\right]\right)$ around the bilateral secondary visual areas, the right cerebellum, and the parahippocampal gyrus and in the left granular retrosplenial cortex (see Figure 6 and Table 5).

\section{DISCUSSION}

Four main results emerged from this fMRI study. First, the neural networks involved in visuo-lingual and visuofacial perception strongly overlap and share similar sensorimotor brain areas. This suggests comparable visual processing of lingual and labial movements, both crucial for the realization of speech sounds. Second, further analyses demonstrate stronger motor and somatosensory activations during visuo-lingual perception and stronger activation of auditory and visual cortices during visuofacial perception. This result suggests more important somatosensory-motor internal simulation of the presented syllables for visuo-lingual speech stimuli that in daily life are clearly audible but not visible, whereas visible and audible visuo-facial speech stimuli seem to strongly rely on well-known sensory representations. Third, behavioral results confirm that both visuo-lingual and visuo-facial speech stimuli were correctly recognized, although to a lower extent and slower for visuo-lingual stimuli. Complementing these findings, activity in the left premotor cortex and in visual brain areas was found to correlate with visual recognition scores observed for visuo-lingual and visuo-facial speech stimuli, respectively, whereas visual activity correlated with RTs for both stimuli. Altogether, these results suggest that visual processing of audible but not visible movements induce motor and visual mental simulation of the perceived speech actions to facilitate recognition and/or learn the association between auditory and visual signals.

\section{Syllable Recognition}

The recognition scores replicated a number of wellknown effects in auditory, visual, and audiovisual speech perception. As expected, perceptual recognition scores show a ceiling effect for auditory and audiovisual modalities. Also consistent with previous studies on unimodal and multimodal speech perception, visual-only syllables 
Figure 5. Surface rendering of brain regions activated showing correlation between visual RTs and neural activity in the audiovisuo-facial $\left(\mathrm{AV}_{\mathrm{F}}\right)$, audio-visuolingual $\left(\mathrm{AV}_{\mathrm{T}}\right)$, visuo-facial $\left(\mathrm{V}_{\mathrm{F}}\right)$, and visuo-lingual $\left(\mathrm{V}_{\mathrm{T}}\right)$ conditions $(p<.05$, FWE corrected; cluster extent threshold of 20 voxels).

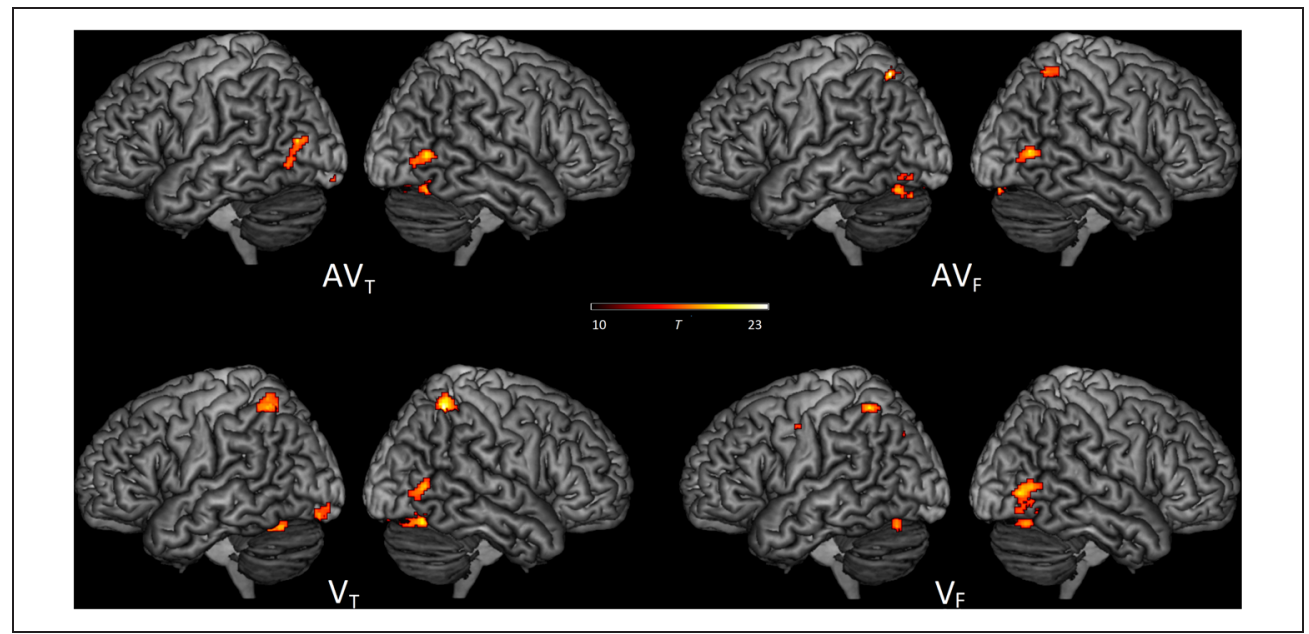

were less well recognized, especially in the case of tongue movements. In addition, in line with previous studies (Katz \& Mehta, 2015; d'Ausilio et al., 2014; Badin et al., 2010), despite lower recognition scores compared with visuo-facial stimuli (and to the other conditions), the recognition of visuo-lingual stimuli remained above chance level.

Regarding RTs, faster recognition was observed when visual information was added to the auditory signal, a result suggesting a temporal advantage of vision on the auditory signal during individual syllable recognition. This effect only happened for familiar visuo-facial speech movements but not for visuo-lingual movements. Contrary to this result, d'Ausilio et al. (2014) found faster RTs for audio-visuo-lingual stimuli when comparing the perception of congruent audio-visuo-lingual syllables with an auditory-only condition with visual noise. The difference between the two studies likely comes from experimental parameters. First, d'Ausilio and colleagues improved the visual recognition of the tongue shape by adding a red line on the tongue surface. In addition, they used more trials, possibly leading to a stronger learning effect for visual tongue movements. Finally, our RTs were calculated from the acoustic onset of the presented consonant, not from the onset of the visual movement, with a clear difference of visual anticipation between labial (strong) and lingual (low) movements. Surprisingly, in our study, audio-visuo-lingual syllables were identified even slower than auditory-only stimuli. This suggests that the sight of tongue movements disrupted and slowed down the final decision processes, even when adding the corresponding auditory signal.

\section{Visuo-lingual and Visuo-facial Speech Stimuli Share a Common Sensorimotor Network}

The fMRI results first demonstrate for visuo-facial and visuo-lingual stimuli common overlapping activity between auditory, visual, and audiovisual modalities in the
pSTS, extending to the adjacent posterior middle temporal gyrus and left V5. These results appear in line with previous studies indicating a key role of this region in speech processing, biological motion perception (including face perception), and audiovisual integration (e.g., Beauchamp, 2005; Beauchamp, Argall, et al., 2004; Beauchamp, Lee, et al., 2004; Calvert et al., 1997, 2000). Additional auditory activity was also observed bilaterally in the posterior temporal gyrus, extending to the right secondary auditory cortex, the parietal operculum, and the antero-ventral part of the inferior parietal lobule.

In addition, strong premotor activity was also observed, mainly in the left hemisphere, and also including activity in the opercular part of the left inferior frontal gyrus, the triangular part of the inferior frontal gyrus, the left anterior IC, and the left primary motor cortex. These motor and premotor activations are in accordance with previous studies on auditory, visual, and audiovisual speech perception showing a key role of motor regions in speech processing (e.g., bski et al., 2013; d'Ausilio et al., 2009, 2011; Sato et ar., 2009, 2010; Möttönen \& Watkins, 2009; Meister et al., 2007; Skipper et al., 2005, 2007; Pekkola et al., 2006; Pulvermuller et al., 2006; Wilson \& Iacoboni, 2006; Ojanen et al., 2005; Callan et al., 2003, 2004; Watkins \& Paus, 2004; Wilson et al., 2004; Calvert \& Campbell, 2003; Jones \& Callan, 2003; Watkins et al., 2003; Campbell et al., 2001; Calvert et al., 2000). It is worthwhile noting that, in this study, participants were only asked to attentively listen to and/or watch speech stimuli. Given the strong motor activity observed in all modalities, it appears quite likely that participants were therefore engaged to some extent in conscious subvocal sensorimotor simulation or covert rehearsal of the presented syllables. This strategy might have occurred especially because of the difficulty to decode visuo-lingual ultrasound images. However, it cannot be concluded whether this subvocal rehearsal strategy was related to some phonetic decision/recognition 
Table 4. Maximum Activation Peaks Showing Correlation between Visual RT and Neural Activity in the (A) Visuo-Lingual ( $\mathrm{V}_{\mathrm{T}}$ ), (B) AudioVisuo-Lingual $\left(\mathrm{AV}_{\mathrm{T}}\right),(\mathrm{C})$ Visuo-Facial $\left(\mathrm{V}_{\mathrm{F}}\right)$, and $(\mathrm{D})$ Audio-VisuoFacial Conditions $\left(\mathrm{AV}_{\mathrm{F}} ; p<.05\right.$, FWE Corrected, Cluster Extent Threshold of 20 Voxels)

\begin{tabular}{llllllll}
\hline & & & \multicolumn{3}{l}{ MNI Coordinates } \\
\cline { 5 - 6 } Regions & $B A$ & $H$ & $x$ & $y$ & $z$ & $t$ \\
\hline
\end{tabular}

A. $V_{T}$

Visual cortex

\begin{tabular}{|c|c|c|c|c|c|c|}
\hline Fusiform gyrus & 37 & $\mathrm{R}$ & 32 & -66 & -20 & 17.40 \\
\hline $\begin{array}{l}\text { Associative visual } \\
\text { cortex (V3) }\end{array}$ & 19 & $\mathrm{R}$ & 50 & -64 & 4 & 15.08 \\
\hline $\begin{array}{l}\text { Associative visual } \\
\text { cortex (V3) }\end{array}$ & 19 & $\mathrm{~L}$ & -26 & -88 & -14 & 14.16 \\
\hline Fusiform gyrus & 37 & $\mathrm{R}$ & 58 & -64 & 4 & 15.27 \\
\hline \multicolumn{7}{|l|}{ Parietal lobule } \\
\hline Intraparietal sulcus & $7 / 40$ & $\mathrm{~L}$ & -30 & -56 & 54 & 19.58 \\
\hline Intraparietal sulcus & $7 / 40$ & $\mathrm{R}$ & 32 & -52 & 56 & 22.61 \\
\hline $\begin{array}{l}\text { Superior parietal } \\
\text { lobule }\end{array}$ & 7 & $\mathrm{~L}$ & -30 & -52 & 52 & 17.42 \\
\hline
\end{tabular}

Other regions

$\begin{array}{lllllll}\text { Cerebellum } & \text { Lobule VI } & \mathrm{R} & 22 & -76 & -20 & 13.00 \\ & & & & & \\ \text { Cerebellum } & \text { Lobule VI } & \text { L } & -28 & -58 & -22 & 16.90\end{array}$

B. $A V_{T}$

Visual cortex

\begin{tabular}{|c|c|c|c|c|c|c|}
\hline $\begin{array}{l}\text { Associative visual } \\
\text { cortex (V3) }\end{array}$ & 19 & $\mathrm{R}$ & & -6 & 2 & 16.75 \\
\hline $\begin{array}{l}\text { Associative visual } \\
\text { cortex (V3) }\end{array}$ & 19 & $\mathrm{~L}$ & & - & -14 & 13.13 \\
\hline $\begin{array}{l}\text { Associative visual } \\
\text { cortex (V2) }\end{array}$ & 18 & & 10 & -88 & -12 & 12.54 \\
\hline $\begin{array}{l}\text { Primary visual } \\
\text { cortex (V1) }\end{array}$ & 17 & $\mathrm{R}$ & 6 & -88 & -10 & 12.26 \\
\hline Fusiform gyrus & 37 & $\mathrm{R}$ & 48 & -72 & -2 & 13.08 \\
\hline $\begin{array}{l}\text { Middle temporal } \\
\text { gyrus }\end{array}$ & 39 & $\mathrm{~L}$ & -38 & -72 & 12 & 16.63 \\
\hline Fusiform gyrus & 37 & $\mathrm{~L}$ & -42 & -66 & -4 & 12.55 \\
\hline $\begin{array}{l}\text { C. } V_{F} \\
\text { Jisual cortex }\end{array}$ & & & & & & \\
\hline $\begin{array}{l}\text { Associative visual } \\
\text { cortex (V2) }\end{array}$ & 18 & $\mathrm{R}$ & 38 & -60 & -6 & 17.84 \\
\hline Fusiform gyrus & 37 & $\mathrm{R}$ & 50 & -72 & 0 & 16.79 \\
\hline
\end{tabular}

Table 4. (continued)

\begin{tabular}{lllllll}
\hline & & \multicolumn{3}{c}{ MNI Coordinates } \\
& Regions & $B A$ & $H$ & $x$ & $y$ & $z$
\end{tabular}

Parietal lobule

Superior parietal

$\begin{array}{llllll}7 & \mathrm{~L} & -34 & -52 & 56 & 17.12\end{array}$

lobule

Motor region

$\begin{array}{lllllll}\text { Premotor cortex } & 6 & \text { L } & -38 & -4 & 44 & 12.46\end{array}$

Other region

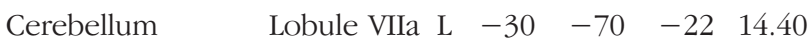

D. $A V_{F}$

Visual cortex

Associative visual cortex (V3)

Associative visual cortex (V3)

Associative visual

cortex (V2)

Primary visual cortex (V1)

Parietal lobule

Superior parietal lobule

Superior parietal lobule

$\begin{array}{llllll}19 & \mathrm{~L} & -34 & -70 & -10 & 13.70\end{array}$

Other regions

Cerebellum

$\begin{array}{llllll}\text { Lobule VI } & \mathrm{R} & 4 & -76 & -12 & 11.40\end{array}$

Cerebellum

$\begin{array}{llllll}\text { Lobule VI } & \text { L } & -34 & -70 & -20 & 14.86\end{array}$

Cerebellum

$\begin{array}{lllll}\text { Lobule VIIa R } & 22 & -84 & -20 & 11.04\end{array}$

Culmen

$\begin{array}{lllll}\mathrm{R} & 8 & -48 & -4 & 14.79\end{array}$

processes or, rather, to an associative learning strategy between the auditory and visual signals. Indeed, the poor temporal resolution of fMRI obviously collapsed the different timings of neural activation corresponding to the "genuine" response in the perceptual/recognition process and the "fake" response caused by such possible mental motor rehearsal, making it difficult to conclude which components are observed.

\section{Neural Specificity of Visuo-lingual and Visuo-facial Processing}

Using a less conservative statistical threshold, a direct comparison of audiovisual and visual conditions related 
Figure 6. Axial views of brain regions showing higher neural responses (condition $\left[\mathrm{AV}_{\mathrm{F}}>\mathrm{A}\right]$ $\left.\cap\left[\mathrm{AV}_{\mathrm{F}}>\mathrm{V}\right]\right)$ in the audio-visuofacial condition; $p<.001$ uncorrected, cluster extent threshold of 20 voxels).

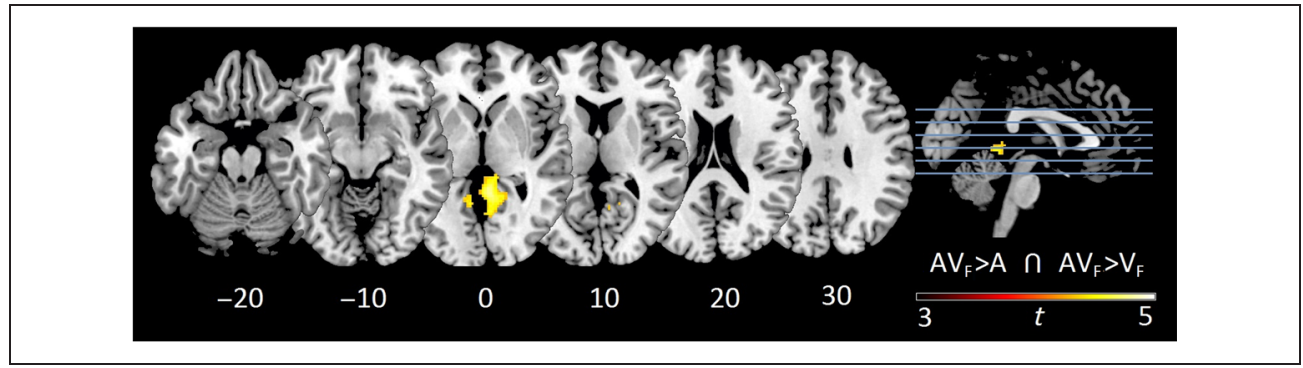

to facial or lingual stimuli demonstrates stronger activation of the premotor regions and the primary somatosensory cortices during the observation of tongue movements. Because tongue movements are not usually visible and participants were not experienced with visuo-lingual ultrasound images, this result could be explained by a more important somatosensory-motor covert simulation of tongue movements and the use of both motor and proprioceptive knowledge, to better achieve a phonetic decoding of the presented visuo-lingual stimuli or to learn the association between the two signals. Apart from covert simulation, another explanation could be related to the unusual nature of the lingual stimuli that might imply increased difficulty and high-level categorization processes in the premotor cortex (Venezia, Saberi, Chubb, \& Hickok, 2012; Sato et al., 2011).

These somatosensory-motor activations appear however reduced for lip movements. This is likely due to the fact that visuo-facial speech stimuli are perceived in daily life, with their processing being more automatized and requiring less motor simulation. In contrast, in both visual and audiovisual conditions related to lip move- ments, stronger visual activity was however observed, extending to a large part of primary and associative visual areas. This result might come from low-level features (contrast, luminance, and motion energy), the facial nature as well as stronger visual experience for facial stimuli. In line with previous studies, our results also showed stronger activity within the auditory cortex during lip reading condition than in the visuo-lingual condition. It was indeed demonstrated that syllables' visual cues are sufficient to activate auditory cortical sites, normally engaged during the perception of heard speech, in the absence of auditory speech sound (Campbell et al., 2001; Calvert et al., 1997). This result suggests a direct matching between the visible articulatory movements and auditory representation of the perceived syllables/phonemes. These stronger visual and auditory activations during facial perception could be the result of projections between auditory and visual regionspossibly mediated by the STS. Indeed, studies have demonstrated direct functional and anatomical pathway between primary sensory areas in nonhuman (Cappe \& Barone, 2005) and human (Eckert et al., 2008; Watkins,

Table 5. Maximum Activation Peaks and Contrast Estimates of Brain Regions Showing Higher Neural Responses in the Audio-VisuoFacial Condition $(p<.001$ Uncorrected, Cluster Extent Threshold of 20 Voxels $)$

\begin{tabular}{|c|c|c|c|c|c|c|c|c|c|c|c|}
\hline \multirow[b]{2}{*}{ Regions } & \multirow[b]{2}{*}{$B A$} & \multirow[b]{2}{*}{$H$} & \multicolumn{3}{|c|}{ MNI Coordinates } & \multirow[b]{2}{*}{$t$} & \multicolumn{5}{|c|}{ Contrast Estimates } \\
\hline & & & $x$ & $y$ & $z$ & & $A$ & $V_{F}$ & $V_{T}$ & $A V_{F}$ & $A V_{T}$ \\
\hline \multicolumn{12}{|l|}{ Visual Cortex } \\
\hline Associative visual cortex (V2) & 18 & $\mathrm{R}$ & 8 & -60 & -2 & 4.12 & 0.06 & 0.14 & 0.11 & 0.27 & 0.10 \\
\hline Associative visual cortex (V2) & 18 & $\mathrm{~L}$ & -10 & -54 & 0 & 3.85 & 0.07 & 0.26 & 0.18 & 0.37 & 0.19 \\
\hline \multicolumn{12}{|l|}{ Cerebellum } \\
\hline Cerebellum (I) & & $\mathrm{R}$ & 4 & -44 & -2 & 4.76 & 0.13 & 0.23 & 0.21 & 0.46 & 0.27 \\
\hline \multicolumn{12}{|l|}{ Other Regions } \\
\hline Parahippocampal gyrus & 30 & $\mathrm{R}$ & 10 & -52 & 4 & 4.58 & 0.08 & 0.20 & 0.17 & 0.32 & 0.16 \\
\hline Parahippocampal gyrus & 30 & $\mathrm{~L}$ & -16 & -52 & 2 & 3.51 & 0.04 & 0.18 & 0.14 & 0.29 & 0.13 \\
\hline Granular retrosplenial cortex & 29 & $\mathrm{~L}$ & -14 & -52 & 6 & 3.72 & 0.02 & 0.10 & 0.09 & 0.20 & 0.08 \\
\hline
\end{tabular}


Shams, Tanaka, Haynes, \& Rees, 2006) cerebral cortex. From that view, lower activation of the visual cortex during the sight of tongue movements could also be explained because such movements are not likely to directly excite the auditory cortex because of their unusual characteristics.

\section{Correlation between Behavioral Performance and Neural Activity}

Interestingly, activities in the left premotor cortex and in visual brain areas were found to correlate with visual recognition scores observed for visuo-lingual and visuofacial speech stimuli, respectively. Hence, the more these areas were activated, the better were the visual recognition scores. These results appear consistent with those observed from the direct comparison between visuo-lingual and visuo-facial movements. As previously noted, given the poor temporal resolution of fMRI, it is however impossible to determine whether motor simulation is related to some recognition/decision processes or rather to some associative learning effect.

Another result is that activity in visual and superior parietal brain areas correlated with RTs for both visuofacial and visuo-lingual stimuli. Given that these brain regions are known to play a role in visual imagery, this later finding might indicate the use of a visual imagery strategy by the participants to learn the association between auditory and visual signals.

\section{Integration between Auditory and Visual Signals}

As previously noted, fMRI studies have demonstrated the existence of specific multisensory brain areas involved in the integration process of auditory and visual signals. More specifically, when compared with auditory and visual unimodal modalities, the observation of audiovisual stimuli was found to induce supra-additive responses in pSTS/pSTG (Beauchamp, 2005; Beauchamp, Argall, et al., 2004; Beauchamp, Lee, et al., 2004; Calvert et al., 2000) as well as subadditive responses in Broca's area (Calvert et al., 2000). Beauchamp (2005) determined two minimal criteria to select brain regions involved in audiovisual speech integration: The region must be activated during auditory, visual, and audiovisual modalities and must display supra-additive audiovisual response. In this study, higher neural responses using the max criterion test ([AV > A $] \cap[\mathrm{AV}>\mathrm{V}]$ ) were only found for audio-visuofacial stimuli around the bilateral secondary visual areas, the right cerebellum, and the parahippocampal gyrus and in the left granular retrosplenial cortex. Although a pSTS/ pSTG activation was observed for all conditions, no higher response was found for this region supposed to be a specific brain area involved in the integration process. Although we do not have a clear explanation for this null result, one possibility is that the strong sensorimotor activity observed in all modalities, including the pSTS/ pSTG, might have changed the classical audiovisual integration network.

\section{Concluding Remarks}

Taken together, our results provide new evidence for an action-perception functional coupling in speech processing. According to a recent neurobiological and perceptuo-motor model of multisensory speech perception by Skipper and colleagues (2007), apart from sensory processing, motor activity during speech perception might partly constrain phonetic interpretation of the sensory inputs through the internal generation of candidate articulatory categorizations and, in return, auditory and somatosensory predictions. In this study, because of the lack of visual knowledge in the processing of the generally hidden tongue movements, a larger motor recruitment could have been necessary to infer appropriate motor speech representations to correctly decode the perceived syllables. This process would have been guided by the participant's expertise in speech production, enabling to transfer procedural motor knowledge into a better understanding of such unfamiliar visual stimuli. One alternative explanation is that motor activity does not directly reflect some phonetic decision processes but rather a learning effect between auditory and visual signals.

Visual and motor familiarities have already been compared in the course of action recognition, and previous studies have shown that the involvement of the motor system during action observation strongly relies on motor learning (e.g., Calvo-Merino et al., 2005, 2006). In line with previous behavioral studies (Katz \& Mehta, 2015; d'Ausilio et al., 2014; Badin et al., 2010), the present data demonstrate that, even if participants have no visual familiarity with one given human action, they are nevertheless able to recognize this action because of their motor knowledge and past auditory and somatosensory experience. This is in line with the assumption of sensorymotor transfer mechanisms at hand in the visual perception of audible but invisible tongue actions. The situation experienced by the participants of the present experiment is to a certain extent similar to the one experienced by newborns and 3-month-old infants, in the classical experiments on facial imitation by Meltzoff and Moore (1977, 1983). They have shown astonishing capacities to replicate to a certain extent a facial movement they have never seen done by a caregiver. These abilities are interpreted by the authors in reference to the link between proprioceptive and motor information feeding newborns with information about their own unseen movements in relation with the visual representation of the perceived movement of the caregiver and enabling the required action matching. Despite the correlational approach used in this study, our results suggest that, even if we have no visual but auditory and somatosensory experiences of an action, the connection between our motor abilities and the visual 
incoming signal exists and enables adequate processing and performance.

\section{UNCITED REFERENCES}

Grabski, Schwartz, et al., 2013

Grabski, Tremblay, Gracco, Girin, \& Sato, 2013

\section{Acknowledgments}

This study was supported by research grants from CNRS (Centre National de la Recherche Scientifique), from Agence Nationale de la Recherche (ANR SPIM, "Imitation in Speech: From Sensorimotor Integration to the Dynamics of Conversational Interaction"), and from the European Research Council (FP7/2007-2013 Grant agreement no. 339152, "Speech Unit(e)s"). Any opinions, findings, and conclusions or recommendations expressed in this material are those of the authors and do not necessarily reflect the views of the funding agencies. We thank Jean-Luc Schwartz for helpful discussions.

Reprint requests should be sent to Avril Treille, GIPSA-lab, UMR 5216, Université Stendhal, 1180, Avenue Centrale, BP25, 38031 Grenoble Cedex 9, France, or via e-mail: avril.treille@gipsa-lab. grenoble-inp.fr.

\section{REFERENCES}

Aziz-Zadeh, L., Iacoboni, M., Zaidel, E., Wilson, S., \& Mazziotta, J. (2004). Left hemisphere motor facilitation in response to manual action sounds. European Journal of Neuroscience, 19, 2609-2612.

Badin, P., Tarabalka, Y., Elisei, F., \& Bailly, G. (2010). Can you "read" tongue movements? Evaluation of the contribution of tongue display to speech understanding. Speech Communication, 52, 493-503.

Beardsworth, T., \& Buckner, T. (1981). The ability to recognize oneself from a video recording of one's movements without seeing one's body. Bulletin of the Psychonomic Society, 18, 19-22.

Beauchamp, M. S. (2005). Statistical criteria in fMRI studies of multisensory integration. Neuroinformatics, 3, 93-114.

Beauchamp, M. S., Argall, B. D., Bodurka, J., Duyn, J. H., \& Martin, A. (2004). Unraveling multisensory integration: Patchy organization within human STS multisensory cortex. Nature Neuroscience, 7, 1190-1192.

Beauchamp, M. S., Lee, K. E., Argall, B. D., \& Martin, A. (2004). Integration of auditory and visual informations about objects in superior temporal sulcus. Neuron, 41, 809-823.

Birn, R. M., Bandettini, P. A., Cox, R. W., \& Shaker, R. (1999). Event-related fMRI of tasks involving brief motion. Human Brain Mapping, 7, 106-114.

Buccino, G., Lui, F., Canessa, N., Patteri, I., Lagravinese, G., Benuzzi, F., et al. (2004). Neural circuit involved in the recognition of actions performed by nonconspecifics: An fMRI study. Journal of Cognitive Neurosciences, 16, 114-126.

Callan, D. E., Jones, J. A., Munhall, K. G., Callan, A. M., Kroos, C., \& Vatikiotis-Bateson, E. (2003). Neural processes underlying perceptual enhancement by visual speech gestures. NeuroReport, 14, 2213-2217.

Callan, D. E., Jones, J. A., Munhall, K. G., Callan, A. M., Kroos, C., \& Vatikiotis-Bateson, E. (2004). Multisensory integration sites identified by perception of spatial wavelet filtered visual speech gesture information. Journal of Cognitive Neuroscience, 16, 805-816.

Calvert, G. A., Bullmore, E., Brammer, M. J., Campbell, R., Iversen, S. D., Woodruff, P., et al. (1997). Silent lip reading activates the auditory cortex. Science, 276, 593-596.

Calvert, G. A., \& Campbell, R. (2003). Reading speech from still and moving faces: The neural substrates of visible speech. Journal of Cognitive Neuroscience, 15, 57-70.

Calvert, G. A., Campbell, R., \& Brammer, M. J. (2000). Evidence from functional magnetic resonance imaging of crossmodal binding in the human heteromodal cortex. Current Biology, 10, 649-657.

Calvo-Merino, B., Glaser, D. E., Grèzes, J., Passingham, R. E., \& Haggard, P. (2005). Action observation and acquired motor skills: An fMRI study with expert dancers. Cerebral Cortex, 15, 1243-1249.

Calvo-Merino, B., Grèzes, J., Glaser, D. E., Passingham, R. E., \& Haggard, P. (2006). Seeing or doing? Influence of visual and motor familiarity in action observation. Current Biology, 16, 1905-1910.

Campbell, R., MacSweeney, M., Surguladze, S., Calvert, G., McGuire, P., Suckling, J., et al. (2001). Cortical substrates for the perception of face actions: An fMRI study of the specificity of activation for seen speech and for meaningless lower-face acts (gurning). Cognitive Brain Research, 12, 233-243.

Cappe, C., \& Barone, P. (2005). Heteromodal connections supporting multisensory integration at low levels of cortical processing in the monkey. European Journal of Neuroscience, 22, 2886-2902.

d'Ausilio, A., Bartoli, E., Maffongelli, L., Berry, J. J., \& Fadiga, L. (2014). Vision of tongue movements bias auditory speech perception. Neuropsychologia, 63, 85-91.

d'Ausilio, A., Bufalari, I., Salmas, P., \& Fadiga, L. (2011). The role of the motor system in discriminating degraded speech sounds. Cortex, 48, 882-887.

d'Ausilio, A., Pulvermüller, F., Salmas, P., Bufalari, I., Begliomini, C., \& Fadiga, L. (2009). The motor somatotopy of speech perception. Current Biology, 19, 381-385.

Di Pellegrino, G., Fadiga, L., Fogassi, L., Gallese, V., \& Rizzolatti, G. (1992). Understanding motor events: A neurophysiological study. Experimental Brain Research, 91, 176-180.

Eckert, M. A., Kamdar, N. V., Chang, C. E., Beckmann, C. F., Greicius, M. D., \& Menon, V. (2008). A crossmodal system linking primary auditory and visual cortices: Evidence from intrinsic fMRI connectivity analysis. Human Brain Mapping, 29, 848-885.

Eickhoff, S. B., Stephan, K. E., Mohlberg, H., Grefkes, C., Fink, G. R., Amunts, K., et al. (2005). A new SPM toolbox for combining probabilistic cytoarchitectonic maps and functional imaging data. Neuroimage, 25, 1325-1335.

Ferrari, P. F., Gallese, V., Rizzolatti, G., \& Fogassi, L. (2003). Mirror neurons responding to the observation of ingestive and communicative mouth actions in the monkey ventral premotor cortex. European Journal of Neuroscience, 17, 1703-1714.

Fogassi, L., Ferrari, P. F., Gesierich, B., Rozzi, S., Chersi, F., \& Rizzolatti, G. (2005). Parietal lobe: From action organization to intention understanding. Science, 308, 662-667.

Gallese, V., Fadiga, L., Fogassi, L., \& Rizzolatti, G. (1996). Action recognition in the premotor cortex. Brain, 119, 593-609.

Doski, K., Schwartz, J. L., Lamalle, L., Vilain, C., Vallée, N., aciu, M., et al. (2013). Shared and distinct neural correlates of vowel perception and production. Journal of Neurolinguistics, 26, 384-408.

(a) bski, K., Tremblay, P., Gracco, V., Girin, L., \& Sato, M. 2013). A mediating role of the auditory dorsal pathway 
in selective adaptation to speech: A state-dependent transcranial magnetic stimulation study. Brain Research, 1515, 55-65.

Hall, D. A., Haggard, M. P., Akeroyd, M. A., Palmer, A. R., Summerfield, A. Q., Elliott, M. R., et al. (1999). Sparse temporal sampling in auditory fMRI. Human Brain Mapping, 7, 213-223.

Haueisen, J., \& Knösche, T. R. (2001). Involuntary motor activity in pianists evoked by music perception. Journal of Cognitive Neuroscience, 13, 786-792.

Howard, R. J., Brammer, M., Wright, I., Woodruff, P. W., Bullmore, E. T., \& Zeki, S. (1996). A direct demonstration of functional specialization within motion-related visual and auditory cortex of the human brain. Current Biology, 6 , 1015-1019.

Hueber, T., Chollet, G., Denby, B., \& Stone, M. (2008). Acquisition of ultrasound, video and acoustic speech data for a silent-speech interface application. In Proceedings of International Seminar on Speech Production (Strasbourg, France) (pp. 365-369).

Johansson, R. (1973). Visual perception of biological motion and a model for its analysis. Perception \& Psychophysics, 14, 201-211.

Jones, J., \& Callan, D. E. (2003). Brain activity during audio-visual speech perception: An fMRI study of the McGurk effect. NeuroReport, 14, 1129-1133.

Katz, W. F., \& Mehta, S. (2015). Visual feedback of tongue movements for novel speech sound learning. Frontiers in Human Neuroscience, 9, 612.

Keysers, C., Kholer, E., Umilta, M. A., Fogassi, L., Gallese, V., \& Rizzolatti, G. (2003). Audiovisual mirror neurons and action recognition. Experimental Brain Research, 153, 628-636.

Kohler, E., Keysers, C., Umilta, M. A., Fogassi, L., Gallese, V., \& Rizzolatti, G. (2002). Hearing sounds, understanding actions: Action representation in mirror neurons. Science, 297, 846-848.

Lahav, A., Saltzman, E., \& Schlaug, G. (2007). Action representation of sound: Audiomotor recognition network while listening to newly acquired actions. Journal of Neuroscience, 27, 3008-3014.

Lancaster, J. L., Woldorff, M. G., Parsons, L. M., Liotti, M., Freitas, C. S., Rainey, L., et al. (2000). Automated Talairach atlas labels for functional brain mapping. Human Brain Mapping, 10, 120-131.

Liberman, A. M., \& Mattingly, I. G. (1985). The motor theory of speech perception revised. Cognition, 21, 1-36.

Loula, F., Prasad, S., Harber, K., \& Shiffrar, M. (2005). Recognizing people from their movements. Journal of Experimental Psychology: Human Perception and Performance, 31, 210-220.

Meister, I. G., Wilson, S. M., Deblieck, C., Wu, A. D., \& Iacoboni, M. (2007). The essential role of premotor cortex in speech perception. Current Biology, 17, 1692-1696.

Meltzoff, A. N., \& Moore, M. K. (1977). Imitation of facial and manual gestures by human neonates. Science, 198, 75-78.

Meltzoff, A. N., \& Moore, M. K. (1983). Newborn infants imitate adult facial gestures. Child Development, 54, 702-709.

Möttönen, R., \& Watkins, K. E. (2009). Motor representations of articulators contribute to categorical perception of speech sounds. Journal of Neuroscience, 29, 9819-9825.

Ojanen, V., Möttönen, R., Pekkola, J., Jääskeläinen, I. P., Joensuu, R., Autti, T., et al. (2005). Processing of audio-visual speech in Broca's area. Neuroimage, 25, 333-338.

Oldfield, R. C. (1971). The assessment and analysis of handedness: The Edinburgh inventory. Neuropsychologia, 9, $97-114$.
Pekkola, J., Laasonen, M., Ojanen, V., Autti, T., Jaaskelainen, L. P., Kujala, T., et al. (2006). Perception of matching and conflicting audio-visual speech in dyslexic and fluent readers: An fMRI study at 3T. Neuroimage, 29, 797-807.

Pickering, M. J., \& Garrod, S. (2013). An integrated theory of language production and comprehension. Behavioral and Brain Sciences, 36, 329-347.

Pizzamiglio, L., Aprile, T., Spitoni, G., Pitzalis, S., Bates, E., D'Amico, S., et al. (2005). Separate neural systems for processing action- or non-action related sounds. Neuroimage, 24, 852-861.

Prather, J. F., Peters, S., Nowicki, S., \& Mooney, R. (2008). Precise auditory-vocal mirroring in neurons for learned vocal communication. Nature, 451, 305-310.

Pulvermuller, F., Huss, M., Kherif, F., Moscosodel Prado Martin, F., Hauk, O., \& Shtyrov, Y. (2006). Motor cortex maps articulatory features of speech sounds. Proceedings of the National Academy of Sciences, U.S.A., 103, 7865-7870.

Rizzolatti, G., \& Craighero, L. (2004). The mirror-neuron system. Annual Review of Neuroscience, 27, 169-192.

Rizzolatti, G., Fadiga, L., Gallese, V., \& Fogassi, L. (1996). Premotor cortex and the recognition of motor actions. Cognitive Brain Research, 3, 131-142.

Rizzolatti, G., Fogassi, L., \& Gallese, V. (2001). Neurophysiological mechanisms underlying the understanding and imitation of action. Nature Review Neuroscience, 2, 661-670.

Sato, M., Buccino, G., Gentilucci, M., \& Cattaneo, L. (2010). On the tip of the tongue: Modulation of the primary motor cortex during audio-visual speech perception. Speech Communication, 52, 533-541.

Sato, M., Grabski, K., Glenberg, A., Brisebois, A., Basirat, A., Ménard, L., et al. (2011). Articulatory bias in speech categorization: Evidence from use-induced motor plasticity. Cortex, 47, 1001-1003.

Sato, M., Tremblay, P., \& Gracco, V. (2009). A mediating role of the premotor cortex in phoneme segmentation. Brain and Language, 111, 1-7.

Saygin, A. P. (2007). Superior temporal and premotor brain areas necessary for biological motion perception. Brain, 130, $2452-2461$.

Schwartz, J. L., Ménard, L., Basirat, A., \& Sato, M. (2012). The Perception for Action Control Theory (PACT): A perceptuo-motor theory of speech perception. Journal of Neurolinguistics, 25, 336-354.

Skipper, J., Van Wassenhove, V., Nussman, H., \& Small, S. L. (2007). Hearing lips and seeing voices: How cortical areas supporting speech production meditate audio-visual speech perception. Cerebral Cortex, 17, 2387-2399.

Skipper, J. I., Nusbaum, H. C., \& Small, S. L. (2005). Listening to talking faces: Motor cortical activation during speech perception. Neuroimage, 25, 76-89.

Stevenson, R. A., Ghose, D., Krueger Fister, J., Sarko, D. K., Altieri, N. A., Nidiffer, A. R., et al. (2014). Identifying and quantifying multisensory integration: A tutorial review. Brain Topography, 27, 707-730.

Tai, Y. F., Scherfler, C., Brooks, D. J., Sawamoto, N., \& Castiello, U. (2004). The human premotor cortex is "mirror" only for biological actions. Current Biology, 14, 117-120.

Venezia, J. H., Saberi, K., Chubb, C., \& Hickok, G. (2012). Response bias modulates the speech motor system during syllable discrimination. Frontiers in Psychology, 3, 157.

Viviani, P., \& Stucchi, N. (1992). Biological movements look uniform: Evidence of motor perceptual interactions. Journal 
of Experimental Psychology: Human Perception and Performance, 18, 603-623.

Watkins, K. E., \& Paus, T. (2004). Modulation of motor excitability during speech perception: The role of Broca's area. Journal of Cognitive Neuroscience, 16, 978-987.

Watkins, K. E., Strafella, A. P., \& Paus, T. (2003). Seeing and hearing speech excites the motor system involved in speech production. Neuropsychologia, 41, 989-994.

Watkins, S., Shams, L., Tanaka, S., Haynes, J. D., \& Rees, G. (2006). Sound alters activity in human V1 in association with illusory visual perception. Neuroimage, 31, 1247-1256.
Wilson, S., \& Iacoboni, M. (2006). Neural responses to nonnative phonemes varying in producibility: Evidence for the sensorimotor nature of speech perception. Neuroimage, 33, 316-325.

Wilson, S. M., Saygin, A. P., Sereno, M. I., \& Iacoboni, M. (2004). Listening to speech activates motor areas involved in speech production. Nature Neuroscience, 7, 701-702.

Zaehle, T., Schmidt, C. F., Meyer, M., Baumann, S., Baltes, C. Boesiger, P., et al. (2007). Comparison of "silent" clustered and sparse temporal fMRI acquisitions in tonal and speech perception tasks. Neuroimage, 37, 1195-1204. 


\section{AUTHOR QUERIES}

\section{AUTHOR PLEASE ANSWER ALL QUERIES}

During the preparation of your manuscript, the questions listed below arose. Kindly supply the necessary information.

1. Please check if affiliations were correctly captured/structured.

2. Please specify which of the two reference items is being referred to in all occurrences of this citation (Grabski et al., 2013).

3. Please provide city and state/country location for this product name (Philips Achieva TX).

4. Please insert citations of uncited references in the body.

\section{END OF ALL QUERIES}

